\title{
Mechanism Dictates Mechanics: A Molecular Substituent Effect in the Macroscopic Fracture of a Covalent Polymer Network
}

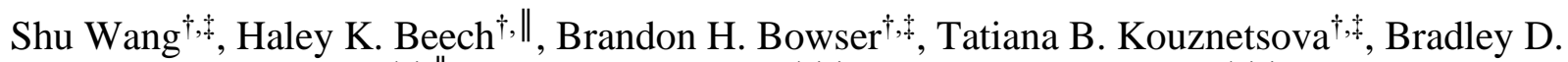

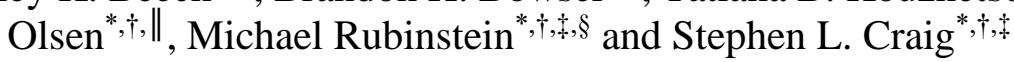

${ }^{\dagger}$ NSF Center for the Chemistry of Molecularly Optimized Networks; ${ }^{\star}$ Department of Chemistry, ${ }^{\S}$ Departments of Physics, Mechanical Engineering, and Biomedical Engineering, Duke University, Durham, North Carolina 27708, United States; "Department of Chemical Engineering, Massachusetts Institute of Technology, Cambridge, Massachusetts 02139, United States

*Bradley D. Olsen, bdolsen@mit.edu

*Michael Rubinstein, mr351@duke.edu

*Stephen L. Craig, stephen.craig@duke.edu

Table of content

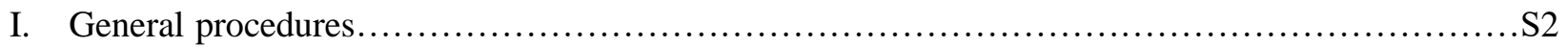

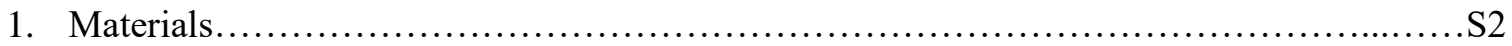

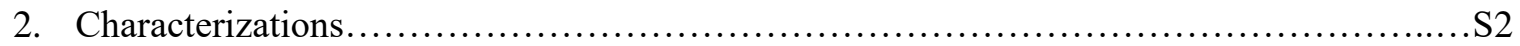

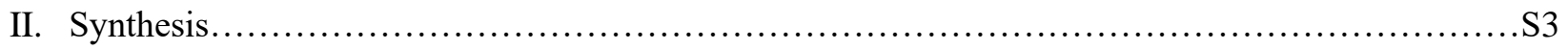

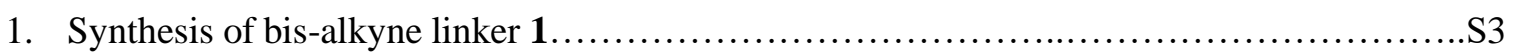

2. Synthesis of bis-alkyne linker 2, polymer PII that contains mechanophore II ................S6

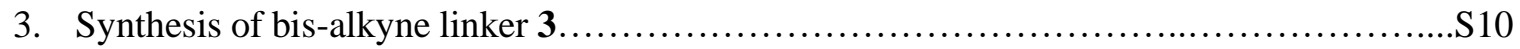

4. Synthesis of azide-terminated 4 -arm PEG............................................

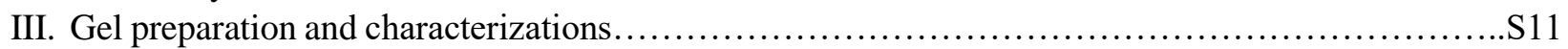

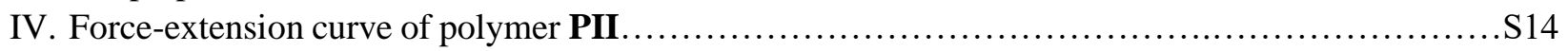

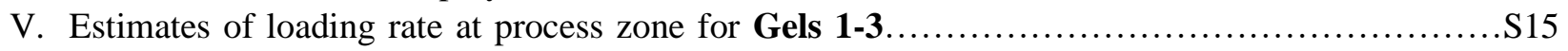



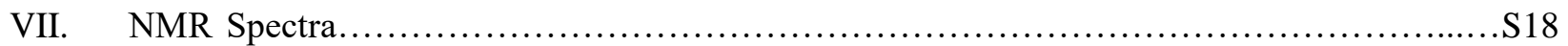

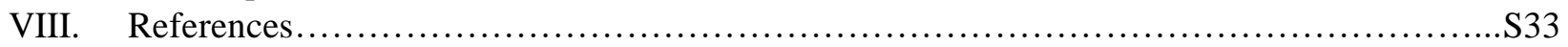




\section{General procedures}

\section{Materials}

Lab general solvents (dichloromethane, acetonitrile, hexane, ethyl acetate, acetone, tetrahydrofuran, dimethyl Sulfoxide) were purchased from VWR or Sigma Aldrich. 4-bromo-cinnamic acid, 1-Undecanol, 4- (dimethylamino)pyridine (DMAP), N,N'-Diisopropylcarbodiimide (DIC), Bis(pinacolato)diboron ((Bpin) $\left.)_{2}\right),[1,1$ '-Bis(diphenylphosphino)ferrocene]dichloropalladium(II) complex with dichloromethane $\left(\mathrm{Pd}(\mathrm{dppf}) \mathrm{Cl}_{2} \cdot \mathrm{DCM}\right)$, potassium acetate (KOAc), acetic acid, $30 \%$ hydrogen peroxide, sodium metabisulfite, Maleic anhydride, cis-buten-1,4-diol, p-toluenesulfonic acid (pTSA), benzophenone, 1-butanol, 3-buten-1ol, Grubbs II catalyst, palladium on carbon, 4-pentenoic anhydride, 9-oxabicyclo[6.1.0]non-4-ene, diethylstilbestrol were purchased from Sigma Aldrich or Alfa Aesar and used without further purification. 4-Pentynoic acid was purchased from Ambeed, Inc..

\section{Characterizations}

NMR and HRMS. ${ }^{1} \mathrm{H}$ NMR and ${ }^{13} \mathrm{C}$ NMR spectra were collected on a $400 \mathrm{MHz}$ Bruker Avance or a 500 $\mathrm{MHz}$ Bruker spectrometer. ${ }^{1} \mathrm{H}$ shifts are reported as chemical shift, multiplicity, coupling constant if applicable, and relative integral. Multiplicities are reported as: singlet (s), doublet (d), doublet of doublets (dd), doublet of triplets (dt), doublet of doublet of doublets (ddd), doublet of doublet of triplets (ddt), triplet $(\mathrm{t})$, triplet of doublets (td), quartet (q), multiplet (m), or broad (br). High-resolution mass spectra were collected on an Agilent LCMS-TOF-DART at Duke University's Mass Spectrometry Facility or an JEOL AccuTOF-DART at Massachusetts Institute of Technology's Mass Spectrometry Facility.

SMFS. The AFM pulling experiments were conducted in toluene at an ambient temperature $\left(\sim 23^{\circ} \mathrm{C}\right)$ in the same manner as described previously ${ }^{1-5}$ using a homemade AFM, which was constructed using a Bruker (previously Digital Instruments) Multimode AFM head mounted on top of a piezoelectric positioner (Physik Instrumente, $\mathrm{GmbH}$ ), similar to the one described in detail previously. ${ }^{6}$ Sharp Microlever silicon probes (MSNL) were purchased from Bruker (Camarillo, CA) and the force curves used for analysis were obtained with rectangular-shaped cantilevers $(205 \mu \mathrm{m}$ x $15 \mu \mathrm{m}$, nominal tip radius $\sim 2 \mathrm{~nm}$, nominal spring constant $\mathrm{k} \sim 0.02 \mathrm{~N} / \mathrm{m}$, frequency $\sim 15 \mathrm{kHz}$ ). Multiple probes of the same type were used throughout the course of the experiments. The spring constant of each cantilever was calibrated in air, using the thermal noise method, based on the energy equipartition theorem as described previously. ${ }^{7}$ Cantilever tips were prepared by soaking in piranha solution for $\sim 15 \mathrm{~min}$ at room temperature. Silicon surfaces were prepared by soaking 
30 min in hot piranha solution, followed by washing with DI-water and drying under a stream of nitrogen. The surface and cantilever were then placed in a UVO cleaner (ozone produced through UV light) for 15 min. After ozonolysis, the cantilever was mounted, and $\sim 20 \mu \mathrm{L}$ of a $\sim 0.1-0.05 \mathrm{mg} \mathrm{mL}^{-1}$ polymer solution was added to the silicon surface and allowed to dry. Measurements were carried out in a fluid cell with scanning set for a series of constant velocity approaching/retracting cycles. To collect 'Force clamp' data cantilever deflection was monitored during each retraction cycle. If it reached threshold value corresponding to $200 \mathrm{pN}$ the system was switched to the force-control mode with the selected set point force value, which it attempted to keep for a set period of time (10-20sec), after which force-control mode was switched off and constant velocity retraction resumed to finish the 'pull'. During acquisition data were filtered at 500Hz. Force curves were collected in dSPACE (dSPACE Inc., Wixom, MI) and Matlab (The MathWorks, Inc., Natick, MA) and analyzed later using Matlab.

GPC. Gel permeation chromatography (GPC) was performed on two Agilent PLgel mixed-C columns (105 $\AA$ A $7.5 \times 300 \mathrm{~mm}, 5 \mu \mathrm{m}$, part number PL1110-6500) using THF (stabilized with 100 ppm BHT) as the eluent. Molecular weights were calculated using a Wyatt Dawn EOS multi-angle light scattering (MALS) detector and Wyatt Optilab DSP Interferometric Refractometer (RI). The refractive index increment (dn/dc) values were determined by online calculation based on injections of known concentration and mass.

\section{Synthesis}

\section{Synthesis of bis-alkyne linker 1}

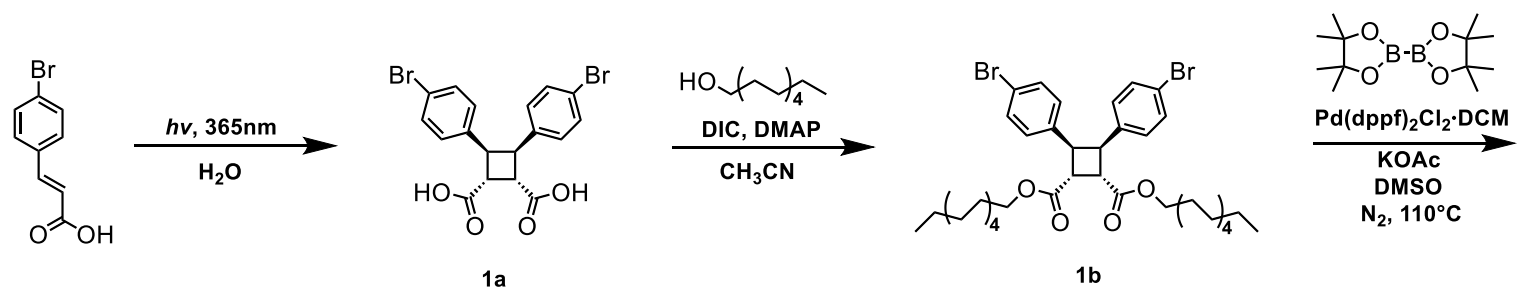

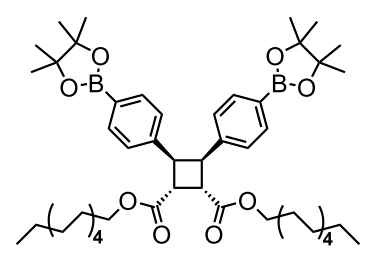

$1 c$
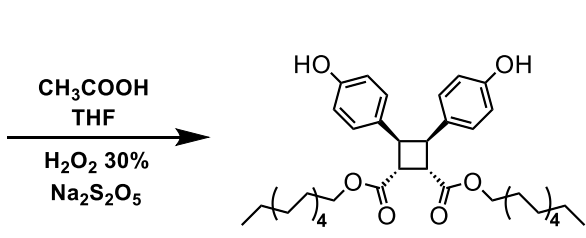

1d

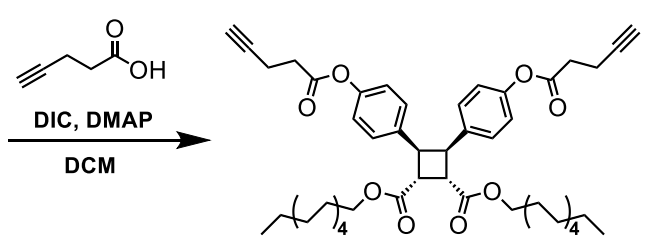

1

Scheme S1. Synthetic route of linker 1. 
Synthesis of 1a. ${ }^{8}$ To a $2 \mathrm{~L}$ conical flask, around $1 \mathrm{~L}$ acetone was added and heated to boiling point. About $15 \mathrm{~g}$ of trans-4-bromo-cinnamic acid was added portion-wise to the boiling acetone. The mixture was stirred and heated until the solid was completely dissolved (more acetone was needed if the solid did not completely dissolve). The solution was cooled down at room temperature overnight to yield needle like $\beta$ trans-4-bromo-cinnamic acid crystal (metastable). The crystal was left at the bottom of the flask, while the acetone was poured into another conical flask for the future preparation of $\beta$-trans-4-bromo-cinnamic acid crystal. To a $500 \mathrm{~mL}$ pyrex conical flask, $400 \mathrm{~mL}$ DI water was added and stirred vigorously with a stir bar. The collected crystal was suspended in the DI water. The suspension was irradiated with $365 \mathrm{~nm}$ UV light for overnight to obtain a cloudy suspension, which was filtrated afterwards to obtained $8 \mathrm{~g}$ of white powder. ${ }^{1} \mathrm{H}$ NMR confirmed the white powder was 1a. ${ }^{1} \mathrm{H}$ NMR (500 MHz, DMSO-d6): $\delta$ 12.48 (s, 2H), 7.13-7.29 $(\mathrm{d}, \mathrm{J}=8.5 \mathrm{~Hz}, 4 \mathrm{H}), 7.03-7.01(\mathrm{~d}, \mathrm{~J}=8.5 \mathrm{~Hz}, 4 \mathrm{H}), 4.20-4.19(\mathrm{~m}, 2 \mathrm{H}), 3.79-3.78(\mathrm{~m}, 2 \mathrm{H}) .{ }^{13} \mathrm{C}$ NMR $(125$ MHz, DMSO-d6): $\delta$ 173.75, 138.63, 130.68, 130.16, 119.23, 43.73, 42.36. HRMS-ESI (m/z): $[\mathrm{M}+\mathrm{H}]^{+}$ calculated for $\mathrm{C}_{18} \mathrm{H}_{14} \mathrm{Br}_{2} \mathrm{O}_{4}, 452.9932$; observed 452.9319 .

Synthesis of 1b. To a $250 \mathrm{~mL}$ round bottom flask (RBF), compound $1 \mathbf{a}(5 \mathrm{~g}, 11 \mathrm{mmol})$ was mixed with $100 \mathrm{~mL}$ acetonitrile. DIC (7 mL, $44 \mathrm{mmol})$ was added dropwise. The solid first dissolved, and then the solution became cloudy again. DMAP (380 mg, $17 \mathrm{mmol})$ and 1-undecanol $(9.15 \mathrm{~mL}, 44 \mathrm{mmol})$ were then added to the solution. The reaction was stirred at r.t. for overnight. After the reaction completed, the solution was filtrated to obtain a yellow solution. The yellow solution was concentrated using rotary evaporator and diluted with $200 \mathrm{~mL}$ DCM. The solution was washed with DI water $(100 \mathrm{~mL} \times 2)$ and brine $(100 \mathrm{~mL} \times 1)$. DCM phase was collected and dried with $\mathrm{Na}_{2} \mathrm{SO}_{4}$. After filtration, the solution was concentrated onto silica. Column chromatography $\left(\mathrm{SiO}_{2}, 0 \sim 10 \%\right.$ EtOAC / hexane gradient eluent) gave compound $\mathbf{1 b}$ as a colorless oil (8 g). ${ }^{1} \mathrm{H}$ NMR $\left(500 \mathrm{MHz}, \mathrm{CDCl}_{3}\right): \delta$ 7.27-7.25 (d, J = 8.5 Hz, 4H), 6.80-6.78 (d, J = 8.5 Hz, 4H), 4.34 - 4.29 (m, 2H), 4.12 (m, 4H), 3.75 - 3.70 (m, 2H), 1.65-1.59 (m, 4H), 1.13-1.23 (m, 32H), 0.89-0.87 (t, J $=6.9 \mathrm{~Hz}, 6 \mathrm{H})$. HRMS-ESI (m/z): $[\mathrm{M}+\mathrm{H}]^{+}$calculated for $\mathrm{C}_{40} \mathrm{H}_{58} \mathrm{Br}_{2} \mathrm{O}_{4}, 761.2775$; observed 761.2767.

Synthesis of 1c. To a $250 \mathrm{~mL}$ RBF, compound $1 \mathrm{~b}(7 \mathrm{~g}, 9.2 \mathrm{mmol})$, (Bpin) 2 (5.13 g, $20.2 \mathrm{mmol})$, $\mathrm{Pd}(\mathrm{dppf}) \mathrm{Cl}_{2} \cdot \mathrm{DCM}(750 \mathrm{mg}, 0.92 \mathrm{mmol})$, KOAc (6 g, $55 \mathrm{mmol}$ ) were mixed with $60 \mathrm{~mL}$ anhydrous DMSO. The mixture was sparged with $\mathrm{N}_{2}$ for 10 minutes and heated up to $110^{\circ} \mathrm{C}$. The solids completely dissolved when the temperature reached $\sim 70^{\circ} \mathrm{C}$, and the solution became dark purple. The reaction was stirred at $110{ }^{\circ} \mathrm{C}$ for overnight. After the reaction completed, the solution was cooled down to r.t. and diluted with DCM $(300 \mathrm{~mL})$. The dilute solution was filtered with Celite ${ }^{\circledR}$. The filtrate was washed with DI water (200 $\mathrm{mL} \times 3)$ and brine $(200 \mathrm{~mL} \times 1)$. DCM phase was collected and dried with $\mathrm{Na}_{2} \mathrm{SO}_{4}$. After filtration, the solution was concentrated onto silica. Column chromatography $\left(\mathrm{SiO}_{2}, 0 \sim 25 \%\right.$ EtOAC / hexane gradient eluent) gave a mixture of compound 1c and monofunctionalized product as blueish solid (5 g). ${ }^{1} \mathrm{H}$ NMR 
suggest the major product was compound 1c. This mixture was used in next step without further purification. ${ }^{1} \mathrm{H}$ NMR (500 MHz, $\left.\mathrm{CDCl}_{3}\right): \delta 7.54-7.52(\mathrm{~d}, \mathrm{~J}=7.6 \mathrm{~Hz}, 4 \mathrm{H}), 6.95-6.93(\mathrm{~d}, \mathrm{~J}=7.6 \mathrm{~Hz}, 4 \mathrm{H}), 4.41$ - 4.39 $(\mathrm{m}, 2 \mathrm{H}), 4.14-4.09(\mathrm{~m}, 4 \mathrm{H}), 3.82$ - $3.80(\mathrm{~m}, 2 \mathrm{H}), 1.64$ - $1.60(\mathrm{~m}, 4 \mathrm{H}), 1.30(\mathrm{~m}, 24 \mathrm{H}), 1.26(\mathrm{~m}, 32 \mathrm{H}), 0.89$ $-0.87(\mathrm{t}, \mathrm{J}=6.9 \mathrm{~Hz}, 6 \mathrm{H})$.

Synthesis of 1d. To a $250 \mathrm{~mL}$ RBF, the crude compound 1c (5g) obtained in last step and acetic acid (5.5 $\mathrm{mL})$ were dissolved in $120 \mathrm{~mL}$ THF. The solution was cooled down in ice water bath. $30 \% \mathrm{H}_{2} \mathrm{O}_{2}(12 \mathrm{~mL})$ was added dropwise. The reaction was stirred at r.t for overnight. After the reaction completed, sodium metabisulfite $(6.6 \mathrm{~g})$ was added. The solution was concentrated with rotary evaporator and diluted with EtOAc $(200 \mathrm{~mL})$. The solution was washed with $\mathrm{DI}$ water $(100 \mathrm{~mL} \times 2)$ and brine $(100 \mathrm{~mL} \times 1)$. EtOAc phase was collected and dried with $\mathrm{Na}_{2} \mathrm{SO}_{4}$. After filtration, the solution was concentrated onto silica. Column chromatography $\left(\mathrm{SiO}_{2}, 0 \sim 40 \%\right.$ EtOAC in hexane, gradient eluent, RediSep Rf Gold Silica Flash Chromatography Column, Teledyne ISCO) gave compound $\mathbf{1 d}$ as a colorless sticky oil (3.5 g). The product turned solid under vacuum. Note that compound 1d should be stored in the freezer (side products were found by NMR after stored at r.t. for a week). ${ }^{1} \mathrm{H} \mathrm{NMR}\left(500 \mathrm{MHz}, \mathrm{CDCl}_{3}\right): \delta 6.75-6.74(\mathrm{~d}, \mathrm{~J}=8.0 \mathrm{~Hz}$, 4H), 6.57 - 6.56 (d, J = 7.9 Hz, 4H), 5.35 - 5.15 (br, 2H), 4.25 - 4.24 (m, 2H), 4.15 - 4.08 (m, 4H), 3.72 $3.71(\mathrm{~m}, 2 \mathrm{H}), 1.64-1.61(\mathrm{~m}, 4 \mathrm{H}), 1.40-1.17(\mathrm{~m}, 32 \mathrm{H}), 0.89-0.87(\mathrm{t}, \mathrm{J}=6.8 \mathrm{~Hz}, 6 \mathrm{H}) .{ }^{13} \mathrm{C}$ NMR $(125$ $\left.\mathrm{MHz}, \mathrm{CDCl}_{3}\right): \delta 172.84,153.91,130.74,128.93,114.85,65.25,44.25,43.61,31.80,29.50,29.49,29.42$, 29.23, 29.17, 28.45, 25.78, 22.57, 13.99. HRMS-ESI (m/z): $[\mathrm{M}+\mathrm{H}]^{+}$calculated for $\mathrm{C}_{40} \mathrm{H}_{60} \mathrm{O}_{6}, 637.4463$; observed 637.4465 .

Synthesis of 1. To a $250 \mathrm{~mL}$ round bottom flask (RBF), compound $1 \mathbf{d}(3.5 \mathrm{~g}, 5.5 \mathrm{mmol})$, 4-Pentynoic acid $(1.13 \mathrm{~g}, 11.5 \mathrm{mmol})$ and DMAP $(0.67 \mathrm{~g}, 5.5 \mathrm{mmol})$ were dissolved with $70 \mathrm{~mL}$ DCM. DIC (2.6 mL, 16.5 mmol) was added dropwise. The reaction was stirred at r.t. for overnight. After the reaction completed, the solution was filtrated and diluted with $50 \mathrm{~mL}$ DCM. The solution was washed with DI water $(100 \mathrm{~mL} \times 2)$ and brine $(100 \mathrm{~mL} \times 1)$. DCM phase was collected and dried with $\mathrm{Na}_{2} \mathrm{SO}_{4}$. After filtration, the solution was concentrated onto silica. Column chromatography $\left(\mathrm{SiO}_{2}, 0 \sim 25 \%\right.$ EtOAC in hexane, gradient eluent) gave compound 1 as a colorless oil (2 g). ${ }^{1} \mathrm{H}$ NMR $\left(400 \mathrm{MHz}, \mathrm{CDCl}_{3}\right): \delta 6.93-6.91(\mathrm{~d}, \mathrm{~J}=8.7 \mathrm{~Hz}, 4 \mathrm{H}), 6.88-$ $6.87(\mathrm{~d}, \mathrm{~J}=8.7 \mathrm{~Hz}, 4 \mathrm{H}), 4.38-4.37(\mathrm{~m}, 2 \mathrm{H}), 4.18-4.07(\mathrm{~m}, 4 \mathrm{H}), 3.77-3.74(\mathrm{~m}, 2 \mathrm{H}), 2.76-2.73(\mathrm{t}, \mathrm{J}=$ $7.4 \mathrm{~Hz}, 4 \mathrm{H}), 2.60-2.57(\mathrm{td}, \mathrm{J}=7.4,2.6 \mathrm{~Hz}, 4 \mathrm{H}), 2.01(\mathrm{t}, \mathrm{J}=2.6 \mathrm{~Hz}, 2 \mathrm{H}), 1.66-1.57(\mathrm{~m}, 4 \mathrm{H}), 1.36-1.26$ (m, 32H), $0.89-0.87(\mathrm{t}, \mathrm{J}=6.9 \mathrm{~Hz}, 6 \mathrm{H}) .{ }^{13} \mathrm{C} \mathrm{NMR}\left(100 \mathrm{MHz}, \mathrm{CDCl}_{3}\right): \delta 172.64,170.50,149.44,136.70$, 129.20, 121.52, 82.44, 69.80, 65.75, 44.75, 44.07, 33.84, 32.32, 30.01, 29.94, 29.74, 29.69, 28.98, 26.30, 23.08, 14.79, 14.51. HRMS-ESI (m/z): $[\mathrm{M}+\mathrm{H}]^{+}$calculated for $\mathrm{C}_{50} \mathrm{H}_{68} \mathrm{O}_{8}, 798.09$; observed 797.4984. 


\section{Synthesis of linker 2 and polymer PII that contains mechanophore II with stored length}

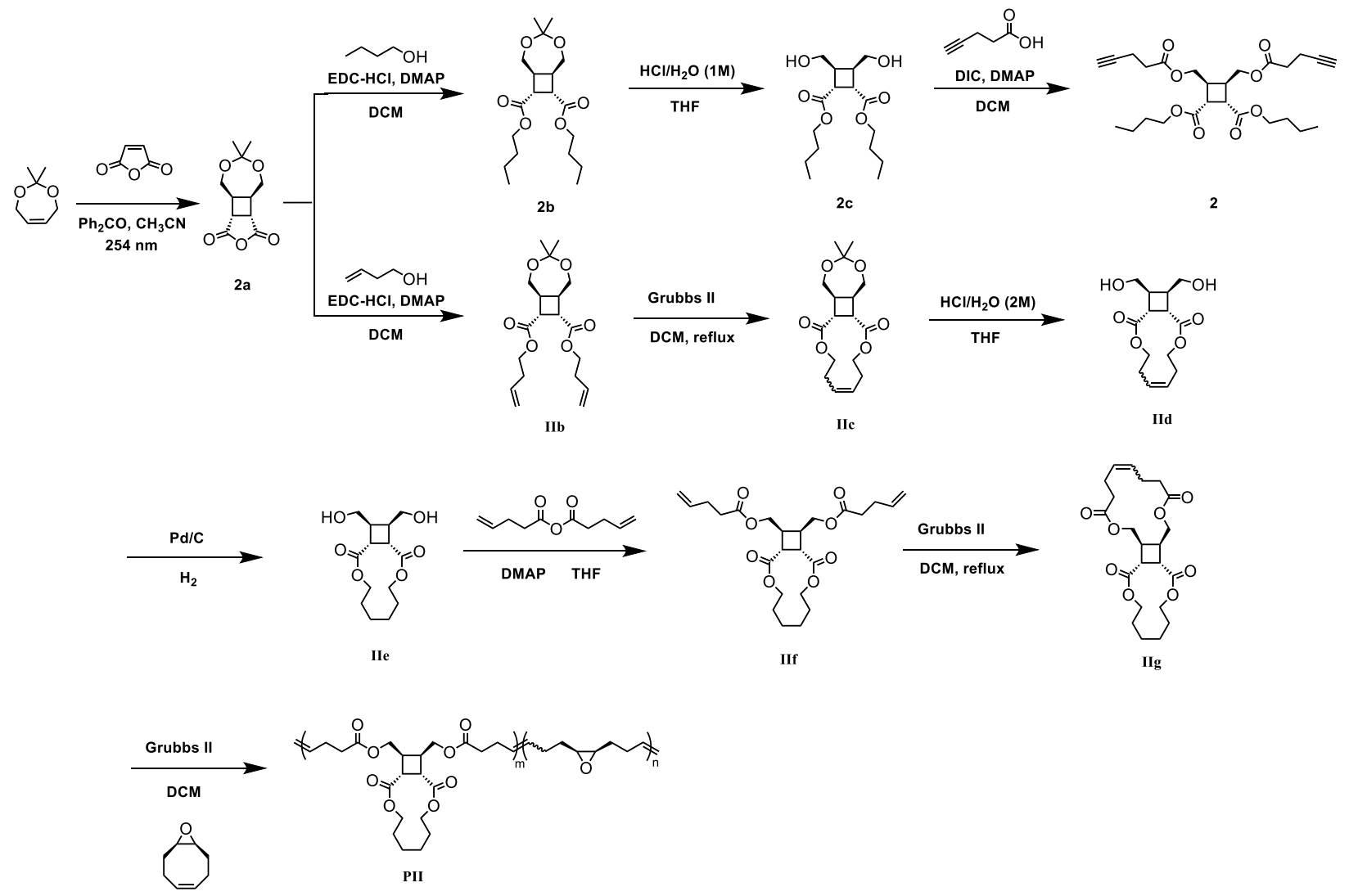

Scheme S2. Synthetic route of linker 2, bis-alkene Mechanophore II with stored length, and polymer PII.

\section{Synthesis of linker 2}

Synthesis of 2a and 2b. 2,2-Dimethyl-1,3-dioxep-5-ene (14 g, $109 \mathrm{mmol}, 1$ eq.), prepared according to literature precedent, ${ }^{9}$ was charged to a $1 \mathrm{~L}$ quartz round bottom flask equipped with a magnetic stir bar along with maleic anhydride (11.8 g, $11.9 \mathrm{mmol}, 1.1 \mathrm{eq}$.) and benzophenone $(5.5 \mathrm{~g})$. Then, $550 \mathrm{~mL}$ of acetonitrile was added to dissolve all components and the colorless solution was sparged with $\mathrm{N}_{2}$ (g) for 10 minutes. Then, the $\mathrm{N}_{2}(\mathrm{~g})$ inlet was removed and the sealed reaction flask was placed in a Rayonet photoreaction chamber and irradiated with UV light $(254 \mathrm{~nm})$ for 50 hours with stirring. After the reaction completed, the solution was concentrated obtain crude product of $2 \mathbf{2 a} .{ }^{1} \mathrm{H}$ NMR suggest the crude product mainly contain benzophenone, maleic anhydride and 2a. To a $500 \mathrm{~mL}$ flask, crude product of $\mathbf{2 a}(31 \mathrm{~g})$ and 1-butanol (24.7 mL, $270 \mathrm{mmol})$ were dissolved with $120 \mathrm{~mL}$ DCM. DMAP (1.1 g, 9 mmol) was then added to the solution. The solution turned dark brown in a few seconds. EDC. $\mathrm{HCl}(34 \mathrm{~g}, 177 \mathrm{mmol})$ was then added portion-wise. The reaction was stirred at r.t. for overnight. After the reaction completed, the solution 
was diluted with $100 \mathrm{~mL} \mathrm{DCM}$ and washed with DI water $(120 \mathrm{~mL} \times 2)$ and brine $(100 \mathrm{~mL} \times 1)$. DCM phase was then dried with $\mathrm{Na}_{2} \mathrm{SO}_{4}$. After filtration, the dark brown solution was then concentrated onto silica. Note that compound $\mathbf{2 b}$ cannot be visualized on TLC with $\mathrm{KMnO}_{4}$ stain. The eluent was chosen based on previous literature with similar structure. ${ }^{9}$ Column chromatography $\left(\mathrm{SiO}_{2}, 0 \sim 25 \%\right.$ EtOAC in hexane, gradient eluent) gave compound $\mathbf{2 b}$ with some impurities as a yellowish liquid (3.2 $\mathrm{g}$ ). The produce was used in next step without further purification. ${ }^{1} \mathrm{H}$ NMR (500 MHz, $\left.\mathrm{CDCl}_{3}\right): \delta 4.07-4.04(\mathrm{~m}, 4 \mathrm{H}), 3.87-$ $3.84(\mathrm{~m}, 2 \mathrm{H}), 3.72-3.69(\mathrm{~m}, 2 \mathrm{H}), 3.24-3.21(\mathrm{br}, 2 \mathrm{H}), 2.86-2.83(\mathrm{br}, 2 \mathrm{H}), 1.60-1.54(\mathrm{~m}, 4 \mathrm{H}), 1.38-$ $1.31(\mathrm{~m}, 10 \mathrm{H}), 0.92-0.89(\mathrm{t}, \mathrm{J}=7.4 \mathrm{~Hz}, 6 \mathrm{H})$.

Synthesis of 2c. To a $1 \mathrm{~L} \mathrm{RBF}$, compound $\mathbf{2 b}(3.2 \mathrm{~g}, 9 \mathrm{mmol})$ was dissolved in $250 \mathrm{~mL}$ of THF and cooled to $0{ }^{\circ} \mathrm{C}$ in an ice-water bath. Then, $125 \mathrm{~mL}$ of a $1 \mathrm{M} \mathrm{HCl}$ solution was added dropwise. The reaction was stirred for 3 hours at $0{ }^{\circ} \mathrm{C}$ and then quenched by the dropwise addition of saturated $\mathrm{NaHCO}_{3}$ (aq) until a pH of 7 was achieved. The solution was concentrated with rotary evaporator and washed with ethyl acetate $(100 \mathrm{~mL} \times 2)$. The combined organic layers were washed with brine $(100 \mathrm{~mL} \times 1)$ and subsequently dried over $\mathrm{Na}_{2} \mathrm{SO}_{4}$. Purification by flash chromatography $\left(\mathrm{SiO}_{2}, 0 \sim 75 \%\right.$ EtOAC in hexane, gradient eluent) furnished compounds $2 \mathrm{c}$ as colorless oil (2.5 g). ${ }^{1} \mathrm{H}$ NMR (500 MHz, DMSO-d6): $\delta 4.63$ (br, 2H), $3.98-$ 3.95 (t, J = 6.6 Hz, 4H), 3.60 - 3.57 (br, 2H), 3.53 - 3.50 (br, 2H) $3.14-3.13$ (d, J = 5.1 Hz, 2H), 2.69 (br, $2 \mathrm{H}), 1.54-1.48(\mathrm{~m}, 4 \mathrm{H}), 1.35-1.27(\mathrm{~m}, 4 \mathrm{H}), 0.89-0.86(\mathrm{t}, \mathrm{J}=7.4 \mathrm{~Hz}, 6 \mathrm{H}) .{ }^{13} \mathrm{C}$ NMR $(125 \mathrm{MHz}, \mathrm{DMSO}-$ d6): $\delta 172.55,63.64,59.86,40.25,39.00,30.15,18.59,13.54$. HRMS-ESI $(\mathrm{m} / \mathrm{z}):[\mathrm{M}+\mathrm{H}]^{+}$calculated for $\mathrm{C}_{16} \mathrm{H}_{28} \mathrm{O}_{6}, 317.1959$; observed 317.1968.

Synthesis of 2. To a $100 \mathrm{~mL}$ RBF, compound $1 \mathrm{~d}$ (7.87 g, $7.5 \mathrm{mmol})$, 4-Pentynoic acid (1.55 g, $15.8 \mathrm{mmol})$ and DMAP (0.92 g, $7.5 \mathrm{mmol})$ were dissolved with $50 \mathrm{~mL}$ DCM. DIC (2.5 mL, $15.8 \mathrm{mmol})$ was added dropwise. The reaction was stirred at r.t. for overnight. After the reaction completed, the solution was filtrated and diluted with $50 \mathrm{~mL}$ DCM. The solution was washed with DI water $(100 \mathrm{~mL} \times 2)$ and brine $(100 \mathrm{~mL} \times 1) . \mathrm{DCM}$ phase was collected and dried with $\mathrm{Na}_{2} \mathrm{SO}_{4}$. After filtration, the solution was concentrated onto silica. Column chromatography $\left(\mathrm{SiO}_{2}, 0 \sim 33 \%\right.$ EtOAC in hexane, gradient eluent) gave linker 2 as a colorless oil (2.4 g). ${ }^{1} \mathrm{H}$ NMR $\left(500 \mathrm{MHz}, \mathrm{CDCl}_{3}\right): \delta 4.27-4.26(\mathrm{~m}, 4 \mathrm{H}), 4.10-4.02(\mathrm{~m}, 4 \mathrm{H})$, $3.24-3.23(\mathrm{~m}, 2 \mathrm{H}), 3.15-3.13(\mathrm{~m}, 2 \mathrm{H}), 2.57-2.54(\mathrm{~m}, 4 \mathrm{H}), 2.50-2.47(\mathrm{~m}, 4 \mathrm{H}), 1.98-1.97(\mathrm{t}, \mathrm{J}=2.6$ $\mathrm{Hz}, 2 \mathrm{H}), 1.61-1.55(\mathrm{~m}, 4 \mathrm{H}), 1.39-1.31(\mathrm{~m}, 4 \mathrm{H}), 0.93-0.90(\mathrm{t}, \mathrm{J}=7.4 \mathrm{~Hz}, 6 \mathrm{H}) .{ }^{13} \mathrm{C}$ NMR $(125 \mathrm{MHz}$, $\mathrm{CDCl} 3): \delta 172.01,171.60,82.37,69.40,65.02,63.55,41.23,36.16,33.42,30.68,19.20,14.45,13.80$. HRMS-ESI (m/z): $[\mathrm{M}+\mathrm{H}]^{+}$calculated for $\mathrm{C}_{26} \mathrm{H}_{36} \mathrm{O}_{8}, 477.2483$; observed 477.2484. 


\section{Synthesis of polymer PII that contains mechanophore II with stored length}

Synthesis of IIb. 2,2-Dimethyl-1,3-dioxep-5-ene (2.56 g, $20 \mathrm{mmol}, 1$ eq.), prepared according to literature precedent, ${ }^{9}$ was charged to a $250 \mathrm{~mL}$ quartz round bottom flask equipped with a magnetic stir bar along with maleic anhydride (4.31g, $20 \mathrm{mmol}, 2.2 \mathrm{eq}$.) and benzophenone $(1 \mathrm{~g})$. Then, $100 \mathrm{~mL}$ of acetonitrile was added to dissolve all components and the colorless solution was sparged with $\mathrm{N}_{2}(\mathrm{~g})$ for 30 minutes. Then, the $\mathrm{N}_{2}(\mathrm{~g})$ inlet was removed and the sealed reaction flask was placed in a Rayonet photoreaction chamber and irradiated with UV light $(254 \mathrm{~nm})$ for 50 hours with stirring. Then, the reaction was removed from the chamber and DMAP (0.54 g, $4.4 \mathrm{mmol}, 0.2$ eq.), EDC (16.8 g, $88 \mathrm{mmol}, 4.4$ eq.), and the corresponding alcohol (132 mmol, 6.6 eq.) were added to the reaction flask. The reaction was allowed to stir at room temperature overnight under ambient conditions. The solvent was then evaporated under reduced pressure and the remaining brown sludge was dissolved in $200 \mathrm{~mL}$ of ethyl acetate. The solution was washed with water $(200 \mathrm{~mL} \times 3)$ and brine $(200 \mathrm{~mL})$. The organic solution was then dried over $\mathrm{Na}_{2} \mathrm{SO}_{4}$. Solvent was removed under reduced pressure and purification by flash chromatography $\left(\mathrm{SiO}_{2}, 0 \sim 10 \%\right.$ EtOAC in hexane, gradient eluent) furnished the desired product as a colorless oil with an isolated yield of $10 \% .{ }^{1} \mathrm{H}$ NMR $\left(500 \mathrm{MHz}, \mathrm{CDCl}_{3}\right): \delta 5.77(\mathrm{ddt}, \mathrm{J}=17.0,10.3,6.7 \mathrm{~Hz}, 2 \mathrm{H}), 5.15-5.03$ (m, 4H), $4.19-4.06(\mathrm{~m}, 4 \mathrm{H}), 3.86(\mathrm{dt}, \mathrm{J}=13.1,2.4 \mathrm{~Hz}, 2 \mathrm{H}), 3.75-3.67(\mathrm{~m}, 2 \mathrm{H}), 3.24(\mathrm{~s}, 2 \mathrm{H}), 2.85$ (s, 2H), 2.37 (qt, J = 6.8, $1.4 \mathrm{~Hz}, 4 \mathrm{H}), 1.38-1.37(\mathrm{~m}, 6 \mathrm{H}) .{ }^{13} \mathrm{C} \mathrm{NMR}\left(125 \mathrm{MHz}, \mathrm{CDCl}_{3}\right): \delta 172.65,133.84$, 117.27, 117.22, 63.86, 61.41, 40.04, 39.42, 32.95, 30.91. HRMS-ESI (m/z): $[\mathrm{M}+\mathrm{H}]^{+}$calculated for $\mathrm{C}_{19} \mathrm{H}_{28} \mathrm{O}_{6}, 353.1959$; found, 353.1952.

Synthesis of IIc. A solution of Grubbs catalyst 2nd generation $(0.2 \mathrm{mmol}, 0.1$ eq. $)$ in $1000 \mathrm{~mL}$ dichloromethane was sparged with $\mathrm{N}_{2}$ (g) for 30 minutes while stirring. To this solution was added dropwise a solution of IIb ( $2 \mathrm{mmol}, 1$ eq.) in $5 \mathrm{~mL}$ of dichloromethane and the reaction was heated to $40{ }^{\circ} \mathrm{C}$ until disappearance of the starting material was observed by TLC. The reaction was cooled to room temperature, then opened to atmosphere and quenched with $3 \mathrm{~mL}$ of ethyl vinyl ether. Purification by flash chromatography $\left(\mathrm{SiO}_{2}, 0 \sim 30 \%\right.$ EtOAC in hexane, gradient eluent) furnished IIc as white solid with an isolated yield of 70\%. ${ }^{1} \mathrm{H}$ NMR (500 MHz, $\left.\mathrm{CDCl}_{3}\right): \delta 5.54-5.34(\mathrm{~m}, 2 \mathrm{H}), 4.46-4.41(\mathrm{~m}, 2 \mathrm{H}), 4.10-3.96$ (m, 2H), $3.87-3.84(\mathrm{~m}, 2 \mathrm{H}), 3.72-3.67(\mathrm{~m}, 2 \mathrm{H}), 3.24(\mathrm{~s}, 2 \mathrm{H}), 2.90$ (d, J = 19.0 Hz, 2H), 2.57 - 2.25 (m, 4H), $1.39-1.32(\mathrm{~m}, 6 \mathrm{H}) .{ }^{13} \mathrm{C}$ NMR $\left(125 \mathrm{MHz}, \mathrm{CDCl}_{3}\right): \delta 172.38,172.25,128.95,128.57,102.42,63.52$, 62.64, 61.84, 61.80, 40.68, 40.34, 39.04, 38.70, 31.98, 27.25, 25.40, 23.69. HRMS-ESI (m/z): [M + Na] ${ }^{+}$ calcd for $\mathrm{C}_{17} \mathrm{H}_{24} \mathrm{O}_{6}, 347.1465$; found, 347.1467.

Synthesis of IId. Compound IIc $(0.85 \mathrm{mmol})$ was dissolved in $25 \mathrm{~mL}$ of THF and cooled to $0{ }^{\circ} \mathrm{C}$ in an icewater bath. Then, $12.5 \mathrm{~mL}$ of a $2 \mathrm{M} \mathrm{HCl}$ solution was added dropwise. The reaction was stirred for 1 hour 
at $0{ }^{\circ} \mathrm{C}$ and then quenched by the dropwise addition of saturated $\mathrm{NaHCO}_{3}(\mathrm{aq})$ until a pH of 7 was achieved. The solution was then allowed to warm to room temperature and was extracted with ethyl acetate $(100 \mathrm{~mL}$ $\times 2$ ). The combined organic layers were washed with brine and subsequently dried over $\mathrm{Na}_{2} \mathrm{SO}_{4}$. Purification by flash chromatography $\left(\mathrm{SiO}_{2}, 0 \sim 70 \%\right.$ EtOAC in hexane, gradient eluent) furnished compounds IId as white solid with an isolated yield of 60\%. ${ }^{1} \mathrm{H} \mathrm{NMR}\left(500 \mathrm{MHz}, \mathrm{CDCl}_{3}\right): \delta 5.57-5.34$ $(\mathrm{m}, 2 \mathrm{H}), 4.47-4.41(\mathrm{~m}, 2 \mathrm{H}), 4.10-3.96(\mathrm{~m}, 2 \mathrm{H}), 3.84-3.77(\mathrm{~m}, 4 \mathrm{H}), 3.24-3.16(\mathrm{~m}, 2 \mathrm{H}), 3.11-2.92$ $(\mathrm{m}, 4 \mathrm{H}), 2.60-2.24(\mathrm{~m}, 4 \mathrm{H}) .{ }^{13} \mathrm{C} \mathrm{NMR}\left(125 \mathrm{MHz}, \mathrm{CDCl}_{3}\right): \delta 172.66,172.47,128.92,128.55,63.73,62.91$, 61.43, 61.40, 40.62, 40.42, 39.42, 39.07, 31.74, 27.23. HRMS-ESI (m/z): $[\mathrm{M}+\mathrm{H}]^{+}$calculated for $\mathrm{C}_{14} \mathrm{H}_{20} \mathrm{O}_{6}$, 285.1333 ; found, 285.1337.

Synthesis of IIe. Diol IId (1 mmol) was dissolved in $10 \mathrm{~mL}$ of dry methanol in a $25 \mathrm{~mL}$ flame-dried, 2neck round bottom flask and sparged with $\mathrm{Ar}$ (g) for 15 minutes. Then, $2 \mathrm{mg}$ of palladium on carbon (10 wt. \% loading) was added and the suspension was further sparged with Ar (g) for 15 minutes. The suspension was then placed under vacuum for 10 seconds and backfilled with $\mathrm{H}_{2}(\mathrm{~g})$ via balloon. The suspension was then sparged with $\mathrm{H}_{2}(\mathrm{~g})$ for 6 hours. Then, the outlet needle was removed, and the suspension was allowed to stir overnight under an atmosphere of $\mathrm{H}_{2}(\mathrm{~g})$. The hydrogen balloon was then removed, and the suspension was sparged with $\operatorname{Ar}(\mathrm{g})$ for 10 minutes and then poured over Celite ${ }^{\circledR}$ and washed with $\mathrm{MeOH}(100 \mathrm{~mL})$. Purification by flash chromatography $\left(\mathrm{SiO}_{2}, 0 \sim 30 \% \mathrm{EtOAC}\right.$ in hexane, gradient eluent) furnished compounds IIe as white solid with an isolated yield of $65 \%$. ${ }^{1} \mathrm{H} \mathrm{NMR} \mathrm{(500} \mathrm{MHz,}$ $\left.\mathrm{CDCl}_{3}\right): \delta 4.45-4.41(\mathrm{~m}, 2 \mathrm{H}), 4.03-3.94(\mathrm{~m}, 2 \mathrm{H}), 3.85-3.79(\mathrm{~m}, 4 \mathrm{H}), 3.29-3.21(\mathrm{~m}, 2 \mathrm{H}), 3.13-2.92$ $(\mathrm{m}, 4 \mathrm{H}), 1.73-1.50(\mathrm{~m}, 8 \mathrm{H}), 1.48-1.36(\mathrm{~m}, 2 \mathrm{H}) .{ }^{13} \mathrm{C} \mathrm{NMR}\left(125 \mathrm{MHz}, \mathrm{CDCl}_{3}\right): \delta 172.87,65.04,61.35$, 40.61, 38.96, 26.31, 24.32. HRMS-ESI (m/z): $[\mathrm{M}+\mathrm{H}]^{+}$calculated for $\mathrm{C}_{14} \mathrm{H}_{22} \mathrm{O}_{6}, 287.1489$; found, 287.1497 .

Synthesis of IIf. Compound IIe (1 mmol, 1 eq.) and 4-dimethylaminopyridine (1.8 mmol, 1.8 equivalent) were dissolved in anhydrous THF $(10 \mathrm{~mL})$ in a $20 \mathrm{~mL}$ scintillation vial. Under an atmosphere of $\mathrm{N}_{2}(\mathrm{~g})$, 4pentenoic anhydride ( $4.4 \mathrm{mmol}, 4.4$ eq.) was added dropwise via syringe and the reaction was stirred at room temperature overnight. Excess anhydride was quenched with $1 \mathrm{~mL} \mathrm{MeOH}$. Purification by flash chromatography $\left(\mathrm{SiO}_{2}, 0 \sim 20 \% \mathrm{EtOAC}\right.$ in hexane, gradient eluent) furnished compounds IIf as colorless oil with yield of $60 \%$. ${ }^{1} \mathrm{H}$ NMR (500 MHz, $\left.\mathrm{CDCl}_{3}\right): \delta 5.85-5.78(\mathrm{~m}, 2 \mathrm{H}), 5.10-4.97(\mathrm{~m}, 4 \mathrm{H}), 4.50-4.39$ $(\mathrm{m}, 2 \mathrm{H}), 4.27-4.16(\mathrm{~m}, 4 \mathrm{H}), 3.99-3.95(\mathrm{~m}, 2 \mathrm{H}), 3.30-3.15(\mathrm{~m}, 4 \mathrm{H}), 2.43-2.33(\mathrm{~m}, 8 \mathrm{H}), 1.69-1.65$ (m, 4H), $1.61-1.53$ (m, 4H), $1.45-1.37$ (m, 2H). ${ }^{13} \mathrm{C}$ NMR (125 MHz, CDCl3): $\delta$ 172.76, 171.81, 136.47, 115.65, 65.14, 63.08, 41.63, 35.59, 33.42, 28.72, 26.37, 24.30. HRMS-ESI (m/z): $[\mathrm{M}+\mathrm{H}]^{+}$calculated for $\mathrm{C}_{24} \mathrm{H}_{34} \mathrm{O}_{8}, 451.2326$; found, 451.2335 .

Synthesis of IIg. An identical procedure to that of compounds IIc was followed, yielding compounds IIg as white solids with a yield of $70 \% .{ }^{1} \mathrm{H}$ NMR (500 MHz, CDCl3): $\delta 5.47-5.54(\mathrm{~m}, 2 \mathrm{H}), 4.48-4.43(\mathrm{~m}$, 
2H), $4.27-4.16(\mathrm{~m}, 4 \mathrm{H}), 4.03-3.94(\mathrm{~m}, 2 \mathrm{H}), 3.30-3.16(\mathrm{~m}, 4 \mathrm{H}), 2.37-2.23(\mathrm{~m}, 8 \mathrm{H}), 1.70-1.66(\mathrm{~m}$, $4 \mathrm{H}), 1.61-1.53(\mathrm{~m}, 4 \mathrm{H}), 1.45-1.39(\mathrm{~m}, 2 \mathrm{H}) .{ }^{13} \mathrm{C} \mathrm{NMR}\left(125 \mathrm{MHz}, \mathrm{CDCl}_{3}\right): \delta 173.24,171.89,130.36$, 65.22, 63.57, 40.02, 35.94, 34.56, 27.70, 26.29, 24.31. HRMS-ESI (m/z): $[\mathrm{M}+\mathrm{H}]^{+}$calculated for $\mathrm{C}_{22} \mathrm{H}_{30} \mathrm{O}_{8}$, 432.2013; found, 432.2015 .

Polymerization of IIg to obtain polymer PII. A $2 \mathrm{~mL}$ crimp top vial was charged with IIg and freshly distilled 9-oxabicyclo[6.1.0]non-4-ene under $\mathrm{N}_{2}$ (g). A stock solution of Grubbs Catalyst 2nd Generation in dry DCM was prepared and sparged with $\mathrm{N}_{2}(\mathrm{~g})$ for $15 \mathrm{~min}$. Then, the Grubbs Catalyst solution $(0.00067$ equiv.) was added via air-tight syringe to dissolve the monomers and initiate the polymerization. After 16 hours, the polymerization was quenched with 10 drops of ethyl vinyl ether and then precipitated into methanol to give the crude polymer. Polymers were purified via one additional precipitation into $\mathrm{MeOH}$ and one reverse precipitation from DCM according to literature precedent. ${ }^{10}$ The polymer was dried on the high vac for at least 1 hour prior to use. ${ }^{1} \mathrm{H}$ NMR (500 MHz, CDCl3): $\delta 5.54-5.35$ (m, 2H), $4.45-4.41$ $(\mathrm{m}, 0.54 \mathrm{H}), 4.24-4.15(\mathrm{~m}, 1.07 \mathrm{H}), 3.97-3.93(\mathrm{~m}, 0.54 \mathrm{H}), 3.28-3.25(\mathrm{~m}, 0.55 \mathrm{H}), 3.19-3.16(\mathrm{~m}, 0.54 \mathrm{H})$, $2.92-2.89(\mathrm{~m} 1.41 \mathrm{H}), 2.39-2.06(\mathrm{~m}, 5.15 \mathrm{H}), 1.69-1.47(\mathrm{~m}, 4.87 \mathrm{H}), 1.46-1.18(\mathrm{~m}, 4.75 \mathrm{H}) .{ }^{1} \mathrm{H} \mathrm{NMR}$ indicates that there were $27 \%$ mechanophore II and $73 \%$ epoxide. GPC: $M_{n}=245 \mathrm{kDa}, \mathrm{M}_{\mathrm{w}}=329 \mathrm{kDa}$, $\mathrm{PDI}=1.3$.

\section{Synthesis of linker 3}
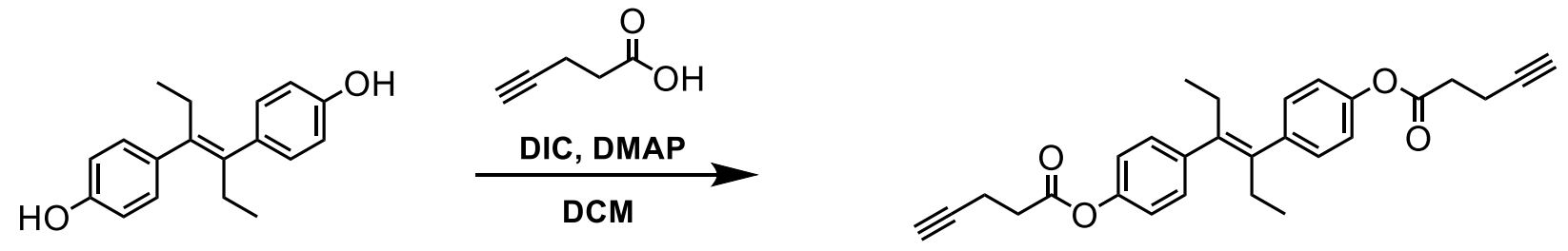

3

Scheme S3. Synthetic scheme of linker 3 .

To a $50 \mathrm{~mL}$ RBF, diethylstilbestrol (1 g, $3.7 \mathrm{mmol})$, 4-Pentynoic acid (0.77 g, $7.8 \mathrm{mmol})$ and DMAP (0.46 $\mathrm{g}, 3.7 \mathrm{mmol})$ were dissolved with $20 \mathrm{~mL}$ DCM. DIC $(1.75 \mathrm{~mL}, 11.1 \mathrm{mmol})$ was added dropwise. The reaction was stirred at r.t. for overnight. After the reaction completed, the solution was filtrated and diluted with $20 \mathrm{~mL}$ DCM. The solution was washed with DI water $(25 \mathrm{~mL} \times 2)$ and brine $(25 \mathrm{~mL} \times 1)$. DCM phase was collected and dried with $\mathrm{Na}_{2} \mathrm{SO}_{4}$. After filtration, the solution was concentrated onto silica. Column chromatography ( $\mathrm{SiO}_{2}, 0 \sim 33 \%$ EtOAC in hexane, gradient eluent) gave linker $\mathbf{3}$ as a white solid (0.65 g). 
${ }^{1} \mathrm{H}$ NMR (500 MHz, $\left.\mathrm{CDCl}_{3}\right): 7.21-7.19(\mathrm{~d}, \mathrm{~J}=8.4 \mathrm{~Hz}, 4 \mathrm{H}), \quad 7.11-7.10(\mathrm{~d}, \mathrm{~J}=8.5 \mathrm{~Hz}, 4 \mathrm{H}), \quad 2.84-$ $2.82(\mathrm{t}, \mathrm{J}=7.3 \mathrm{~Hz}, 4 \mathrm{H}), 2.67-2.64(\mathrm{~m}, 4 \mathrm{H}), 2.14-2.10(\mathrm{q}, \mathrm{J}=7.4 \mathrm{~Hz}, 4 \mathrm{H}), 2.06-2.04$ (t, J = 2.6 Hz, 2H), $0.78-0.75$ (t, J = $7.4 \mathrm{~Hz}, 6 \mathrm{H}) .{ }^{13} \mathrm{C} \mathrm{NMR}\left(125 \mathrm{MHz}, \mathrm{CDCl}_{3}\right) \delta 170.77,149.45,140.46,139.27,130.04$, 121.43, 82.50, 69.82, 33.94, 28.89, 14.90, 13.65. HRMS-ESI $(\mathrm{m} / \mathrm{z}):[\mathrm{M}+\mathrm{H}]^{+}$calculated for $\mathrm{C}_{28} \mathrm{H}_{28} \mathrm{O}_{4}$, 429.53; observed 429.2061.

\section{Synthesis of azide-terminated 4-arm PEG $^{11}$}
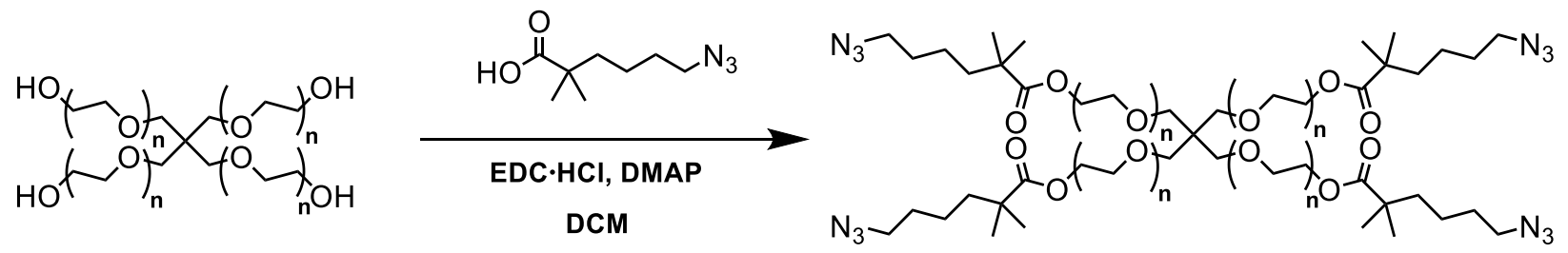

Scheme S3. Synthetic scheme of azide-terminated 4-arm PEG.

The 4-arm PEG 5000 (Creative PEGWorks, actual MW = $5108 \mathrm{~g} / \mathrm{mol}$ ) was dissolved in minimal ethyl acetate, precipitated by dropwise addition to a stirring beaker of cold diethyl ether, and dried for at least 12 hours in a vacuum oven before use. To a $100 \mathrm{~mL}$ flame-dried Schlenk flask was added $3.0 \mathrm{~g}(0.59 \mathrm{mmol})$ of 4-arm PEG, $2.25 \mathrm{~g}(11.8 \mathrm{mmol}) \mathrm{EDC} \cdot \mathrm{HCl}, 0.62 \mathrm{~g}(5.0 \mathrm{mmol})$ 4-dimethylaminopyridine, and $1.09 \mathrm{~g}$ (5.9 mmol) of 6-azido-2,2-dimethylhexanoic acid ${ }^{11}$. After addition, the flask was evacuated and refilled with nitrogen three times. The starting materials were dissolved in minimal amount of dry DCM. The reaction was stirred at r.t. for 24 hours. After the reaction completed, the solution was poured into $50 \mathrm{ml}$ water and washed twice with water and twice with brine. The organic phase was dried with sodium sulfate and concentrate with rotary evaporator. After the solution became viscous, the PEG was precipitated directly by dropwise addition to a stirring beaker of cold diethyl ether and the PEG was collected on a Buchner funnel. Repeat the precipitation twice, and the final product was dried and collected as a white powder with a $79 \%$ yield (2.68 g). ${ }^{1} \mathrm{H}-\mathrm{NMR}\left(400 \mathrm{MHz} \mathrm{CDCl}_{3}\right) \delta: 4.24(\mathrm{t}, 8 \mathrm{H}), 3.73-3.54(\mathrm{~m}, 464 \mathrm{H}), 3.28(\mathrm{t}, 8 \mathrm{H})$, 1.65-1.55 (m, 16H), 1.37-1.29 (m, 8H), 1.20 (s, 24H).

\section{Gel preparation and Gel characterizations}

Gel preparation. A $50 \mathrm{mg} / \mathrm{ml} \mathrm{CuBr}$ catalyst solution for the copper catalyzed alkyne azide click chemistry (CuCAAC) was prepared in propylene carbonate according to literature procedure. ${ }^{12}$ All gels for this study were synthesized at $25 \mathrm{mM}$ ( $10 \mathrm{wt} \%)$ PEG concentration. Four-arm azide-functionalized PEG (794.2 mg) 
and the corresponding stoichiometric amount of mechano-sensitive crosslinker (219.2 mg, $131.1 \mathrm{mg}$, and $117.9 \mathrm{mg}$ for weak, medium, and strong crosslinkers, respectively) were massed into an $8 \mathrm{ml}$ scintillation vial and brought into the glovebox. The solids were dissolved in $3.915 \mathrm{ml}$ propylene carbonate and vortexed; complete dissolution of the strong and weak bonds often took up to an hour. Two stoichiometric equivalents of copper catalyst solution, based on reactive group $(1.578 \mathrm{ml})$, were added via micropipette followed by vortexing. The solution was transferred to a $5.5 \times 10 \times 0.1 \mathrm{~cm}$ Teflon mold via syringe, gently tapped to release any bubbles, and left to react in the glovebox for 24 hours to ensure complete conversion of the reactive groups, as verified with FT-IR.

\section{Gel characterizations and mechanical testing}

Rheology. Rheological measurements were conducted on an Anton Paar MCR 301 rheometer with a disposable $10 \mathrm{~mm}$ parallel plate geometry. Samples were cut to size with a $10 \mathrm{~mm}$ diameter biopsy punch. The plates were covered with adhesive sandpaper to prevent slipping (Norton, A275, 120 grit, Aluminum Oxide). Frequency sweep measurements were conducted at $23{ }^{\circ} \mathrm{C}$ with a constant $0.5 \%$ shear strain, well within the linear viscoelastic regime based on initial strain sweeps. Constant temperature was maintained with a Peltier temperature control stage. Three samples from different positions in the gel were punched out for shear moduli measurement. Note that the loss moduli at low frequency typically have a large degree of error due to poor instrument sensitivity.

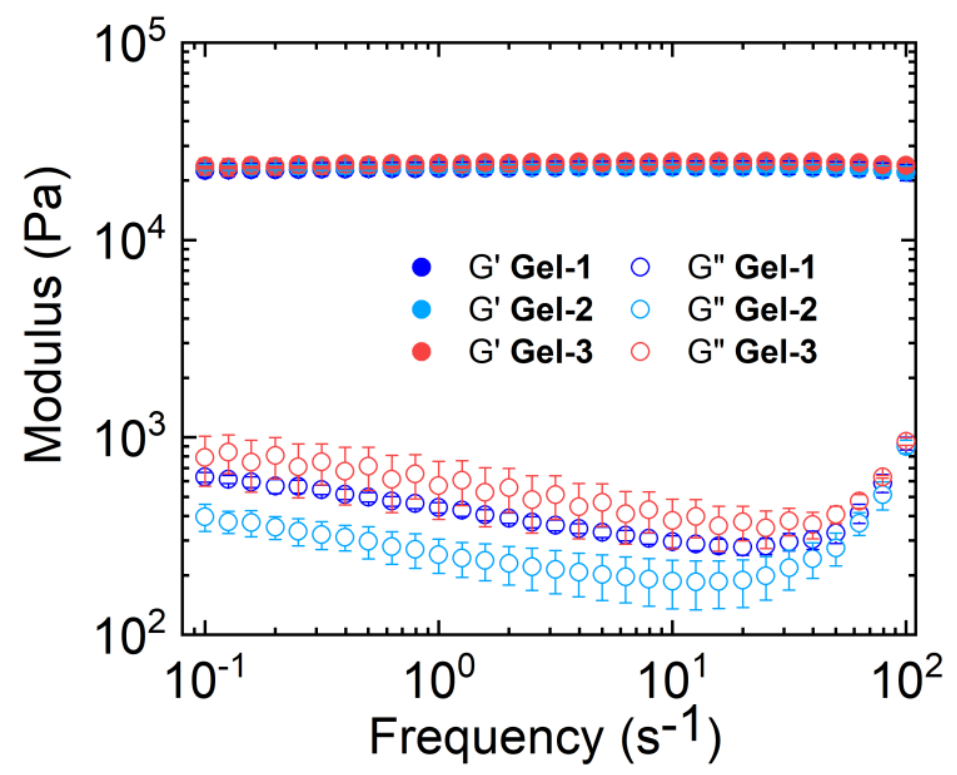

Figure S1. Frequency sweep of Gels 1-3 at the as-prepared state. 
FT-IR. Fourier-transform infrared attenuated total reflectance (FTIR-ATR) spectroscopy was performed on a Bruker Alpha II FTIR spectrometer with a Diamond Crystal ATR accessory. Disappearance of the alkyne and azide IR peaks was confirmed for all of the gels synthesized.

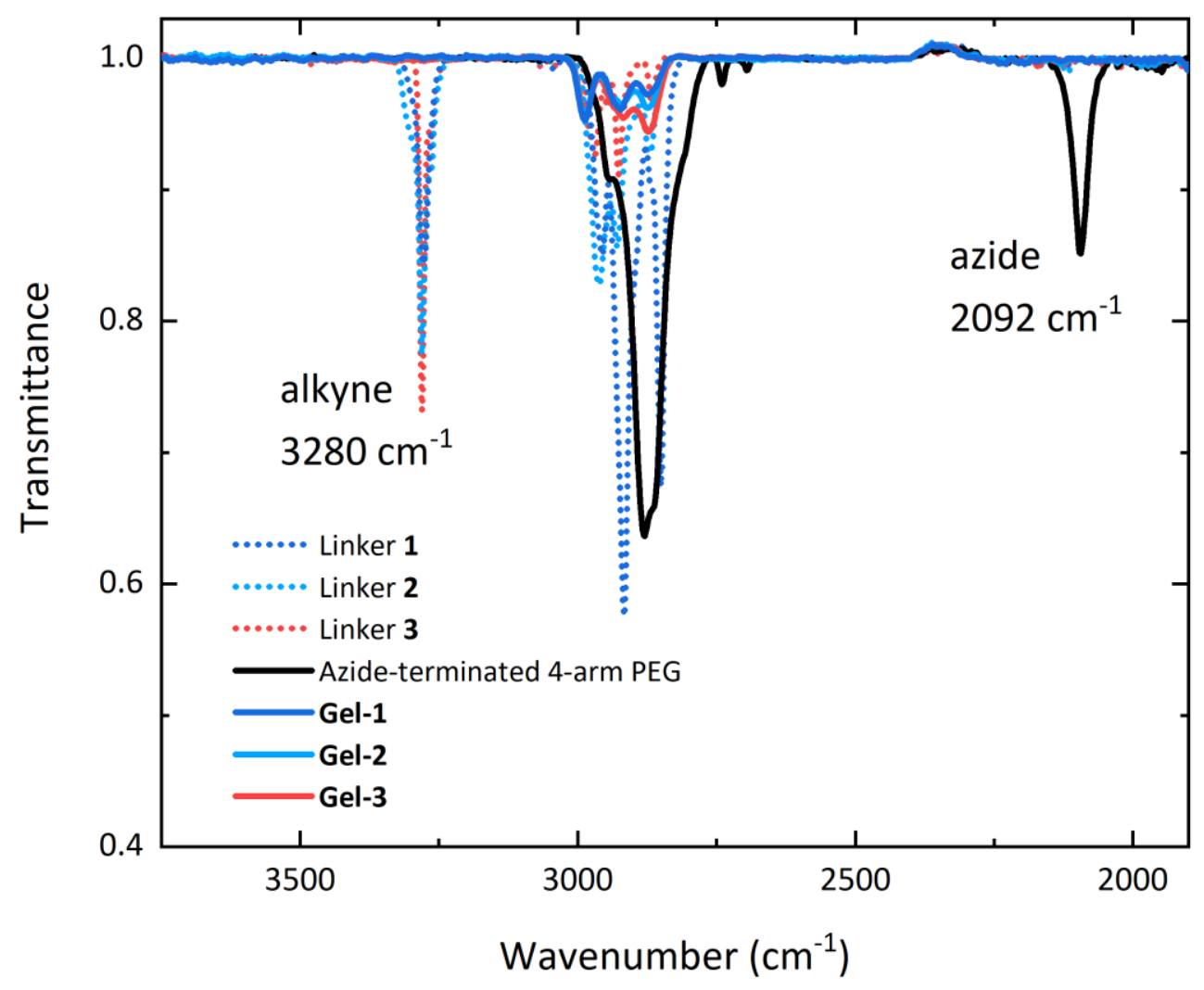

Figure S2. FTIR-ATR spectra of linkers 1-3, azide-terminated 4-arm PEG and Gels 1-3 show the disappearance of alkyne and azide peaks of linkers and azide-terminated 4-arm PEG.

Tearing energy. Samples for tearing energy were cut with a razor blade as a $20 \times 20 \mathrm{~mm}$ square. This was reduced to a $20 \times 4 \mathrm{~mm}$ area after clamping. Each measurement used 3 un-notched samples and 5 notched samples; for notched samples, a $5 \mathrm{~mm}$ cut was made in the center of one side of the piece, perpendicular to the edge. The exact thickness, width, and cut length were measured with calipers and a ruler before measurement. Samples were loaded into the clamps at a gauge length of $\sim 2 \mathrm{~mm}$, then stretched to a force of $0.01 \mathrm{~N}$, which resulted in an initial gauge length of $4 \pm 0.5 \mathrm{~mm}$. Unnotched samples were pulled to $100 \%$ strain or failure (Gel-1) and notched samples were pulled to failure at a constant rate of $0.011 \mathrm{~mm} / \mathrm{s}$ $(0.66 \mathrm{~mm} / \mathrm{min})$. Tearing energy was calculated using the Thomas-Rivlin method ${ }^{13}$ where the strain energy 
is obtained by integrating the un-notched stress-strain curve to the strain at which the crack of the notched samples began to propagate.

Equilibrium swelling and sol fraction measurements. Disks for swelling were punched out with a 10 mm biopsy punch; four replicates were made for each gel. The initial mass of each disk was recorded and used to calculate the pre-gel mass of polymer. Each sample was submerged in $10 \mathrm{ml}$ water and solvent exchanged every 12 hours to facilitate extraction of the copper. After the disks had equilibrated (typically after 5 solvent exchanges, based on $<1 \%$ mass change between exchanges) they were either lyophilized so the dry polymer mass could be recorded to calculate the sol fraction, or solvent exchanged with THF until equilibrated to calculate the equilibrium swelling (Figure 2c). The sol fractions were calculated to be: 0.053 $\pm 0.013,0.021 \pm 0.008$ and $0.042 \pm 0.02$ for Gel 1-3, respectively. After equilibrium was achieved in THF, samples were dried in a vacuum oven to record the dry polymer mass.

\section{Force-extension curve of polymer PII}

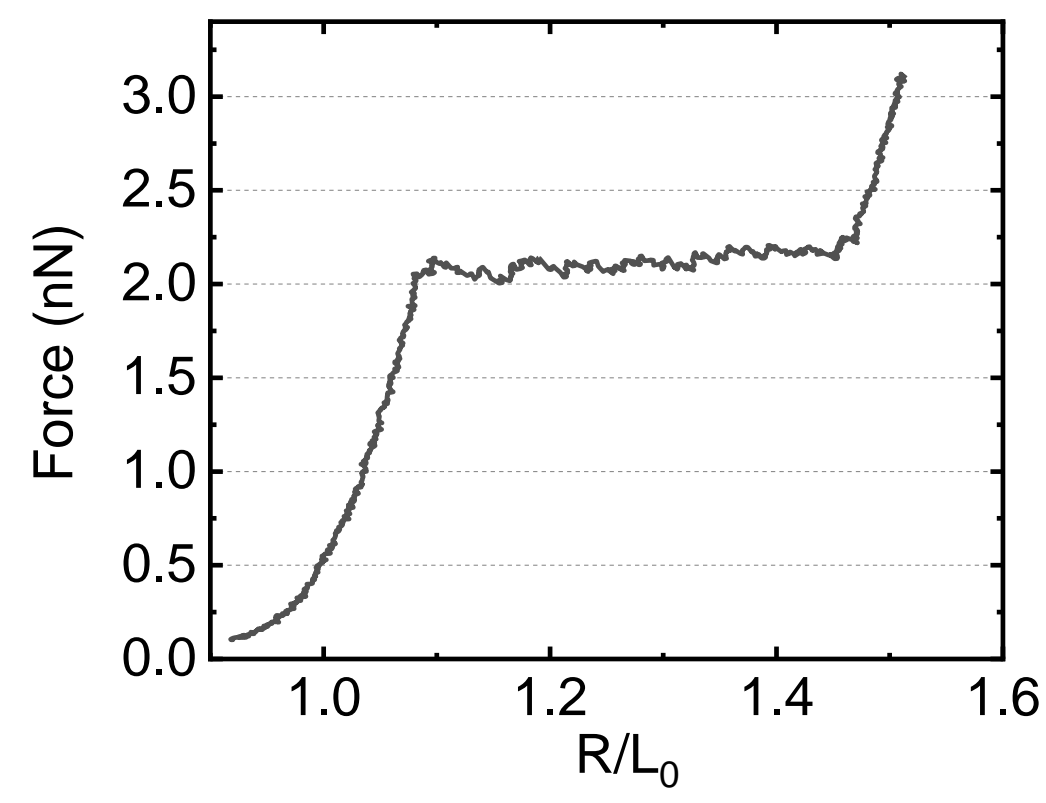

Figure S3. Representative force-extension curve for polymer PII. Horizontal dashed lines are the guide of force. Mechanophore II can be activated at around $2.1 \pm 0.1 \mathrm{nN}$ with $300 \mathrm{~nm} / \mathrm{s}$ pulling rate and $\sim 20 \mathrm{pN} / \mathrm{nm}$ spring constant of cantilever. 


\section{Estimates of loading rate at process zone for Gels 1-3}

For notched samples of Gels 1-3, by knowing the displacements of clamps in the range that the stress drops to zero and the pulling rate, the time required to completely break the sample can be obtained. The curve that has the steepest drop has been taken to estimate a lower limit of the time which is about $1 \mathrm{~s}$. In addition, based on the cut length $\mathrm{c} \approx 4 \mathrm{~mm}$ and the width of the sample $\approx 20 \mathrm{~mm}$, assuming the crack propagates in a straight line, we obtained that there is $\approx 16 \mathrm{~mm}$ for the crack to propagate across the whole sample. Thus, the upper limit of crack growth rate $\dot{a}$ can be estimated to be around $0.016 \mathrm{~m} / \mathrm{s}$. We then used this upper limit for the rest of the estimation.

Based on fracture mechanics, the strain rate $\dot{\varepsilon}$ at the process zone can be estimated: ${ }^{14}$

$$
\dot{\varepsilon} \cong \frac{\pi K_{c} \dot{a}}{E\left(2 \pi r_{p}\right)^{3 / 2}}
$$

where $K_{c} \sim \sqrt{ }(E \cdot \Gamma)$ is the critical stress intensity factor, $\dot{a}$ is the crack growth rate, $E$ is Young's modulus. The process zone size $r_{p}$ can be estimated by crack-tip field: ${ }^{15}$

$$
r_{p} \cong \frac{1}{2 \pi}\left(\frac{K_{c}^{2}}{\sigma_{y}^{2}}\right)
$$

where $\sigma_{y}$ is the yield strength.

Since the yield strengths are not known for Gels 1-3, we characterized the tensile strengths $\sigma_{t}$ of Gels 1-3 as estimates for the yield strengths. The samples of Gels 1-3 at the as-prepared state were cut into dog-bone shape and the tensile strengths were measured. Three samples were tested for each gel and the average values for Gels 1-3 are measured to be $31 \mathrm{kPa}, 55 \mathrm{kPa}$, and $80 \mathrm{kPa}$, respectively. Therefore, based on $E, \Gamma$, $\dot{a}$ and $\sigma_{y} \approx \sigma_{t}$, we calculated the strain rate at the process zone for Gels 1-3. The data that were used are summarized in Table $\mathbf{S 1 .}$

Table S1. Data used to estimate the strain rates at the process zone for Gels 1-3.

\begin{tabular}{cccccccc}
\hline Gel & $\boldsymbol{E}(\mathbf{k P a})$ & $\boldsymbol{\Gamma}\left(\mathbf{J} / \mathbf{m}^{\mathbf{3}}\right)$ & $\begin{array}{c}\boldsymbol{K}_{\boldsymbol{c}} \\
\left(\mathbf{N} / \mathbf{m}^{\mathbf{1 . 5}}\right)\end{array}$ & $\boldsymbol{\sigma}_{t}(\mathbf{k P a})$ & $\dot{\boldsymbol{a}}(\mathbf{m} / \mathbf{s})$ & $\boldsymbol{r}_{\boldsymbol{p}}(\mathbf{m})$ & $\dot{\varepsilon}\left(\mathbf{s}^{\mathbf{- 1}}\right)$ \\
\hline $\mathbf{1}$ & 69 & 3.4 & 484 & 31 & 0.016 & $3.9 \cdot 10^{-5}$ & 93 \\
$\mathbf{2}$ & 69.6 & 10.6 & 859 & 55 & 0.016 & $3.9 \cdot 10^{-5}$ & 163 \\
$\mathbf{3}$ & 73.2 & 27.1 & 1408 & 80 & 0.016 & $4.9 \cdot 10^{-5}$ & 177 \\
\hline
\end{tabular}


As calculated above, the strain rates at the process zone for Gels 1-3 are all around $100 \mathrm{~s}^{-1}$. We assume that the process zone deforms affinely, and the strain rate of a single chain is the same as the strain rate of the process zone. According to SMFS characterization of linear PEG, ${ }^{16}$ the stretch stiffness is $100 \mathrm{nN}$, which means the force along the chain increases $100 \mathrm{nN}$ per $100 \%$ strain. Hence, the single-chain loading rate $\mu$ is estimated to be around $10^{4} \mathrm{nN} / \mathrm{s}$.

\section{Estimates of molecular activation forces for Gels 1-3}

Mechanophore I has been characterized to have a rate constant of about $17 \mathrm{~s}^{-1}$ at around $1 \mathrm{nN} .{ }^{17}$ The calculations predict the rate increases by roughly a factor of 10 for every additional $70 \mathrm{pN}$ of force when the benzylic diradical transition state is rate-determining. ${ }^{17}$ Based on the Bell model,${ }^{18}$ we can estimate the distance between reactant and the transition state of mechanophore $\mathbf{I}$ to be $\Delta x_{I}^{\ddagger} \approx 0.14 \mathrm{~nm}$. The Bell model gives the rate-force dependence:

$$
\ln (k(f))=\ln \left(\frac{\mu \cdot \Delta x^{\ddagger}}{k_{B} T}\right)=\frac{\Delta x^{\ddagger}}{k_{B} T} \cdot f+\ln \left(k_{0}\right)
$$

where $k(f)$ is the rate constant at force $f, k_{B} T$ is the thermal energy, and $k_{0}$ is the rate constant without applied force. Based on this relationship, the rate constant at the loading rate of $10^{4} \mathrm{nN} / \mathrm{s}$ is estimated to be $3.4 \cdot 10^{5}$ $\mathrm{s}^{-1}$, and the average force at break is estimated to be about $1.3 \mathrm{nN}$.

The activation force of mechanophore II at $10^{4} \mathrm{nN} / \mathrm{s}$ can be estimated based on the simulation by Boulatov and coworkers on an analogous cyclobutane pulled from cis-diester substituents. ${ }^{17}$ We therefore use the simulated data as an estimate for the force coupled reactivity of mechanophore II. The calculations predict the rate of this analogous cyclobutane increases by roughly a factor of 10 for every additional $120 \mathrm{pN}$ of force when the diradical (at alpha carbon of ester groups) transition state is rate-determining. Based on the Bell model, we can estimate the distance between reactant and the transition state of mechanophore II to be $\Delta x_{I I}^{t} \approx 0.08 \mathrm{~nm}$. Based on Figure S3, the rate constant at around $2.1 \mathrm{nN}$ has been estimated to be about $5 \mathrm{~s}^{-1}$. Therefore, a similar calculation can be done to obtain the rate constant for mechanophore II at a loading rate of $10^{4} \mathrm{nN} / \mathrm{s}$ to be around $2.0 \cdot 10^{5} \mathrm{~s}^{-1}$ and the average force at break is estimated to be about 2.6 $\mathrm{nN}$.

For the polymer chains made from structure III, calculations by Smalø and Uggerud ${ }^{19}$ have provided an estimate for the rate-force dependence of the triazole $\alpha$-cleavage reaction under tension. The rate increases by roughly a factor of 10 for every additional $70 \mathrm{pN}$ of force when the triazole $\alpha$-cleavage is the reaction pathway. Unlike mechanophore I and II, the triazole $\alpha$-cleavage reaction has not been characterized by 
experiments. To estimate the activation force at a loading rate of $10^{4} \mathrm{nN} / \mathrm{s}$, we extrapolate the activation energy versus force plot in the paper mentioned above to about $60 \sim 70 \mathrm{~kJ} / \mathrm{mol}$, which is the roughly the same as the activation energies of mechanophore $\mathbf{I}$ and $\mathbf{I I}$ at the loading rate of $10^{4} \mathrm{nN} / \mathrm{s}$. At this activation energy, the force is around $3.8 \mathrm{nN}$.

To compare the tearing energies and the activation forces, we plot $\Gamma \sim f_{\text {break }}{ }^{a}$ in Figure S4. The parameter $a$ $=1.9$, which is very close to the "coupled-spring" model based on the adjustments to the Lake-Thomas theory. ${ }^{20,21}$

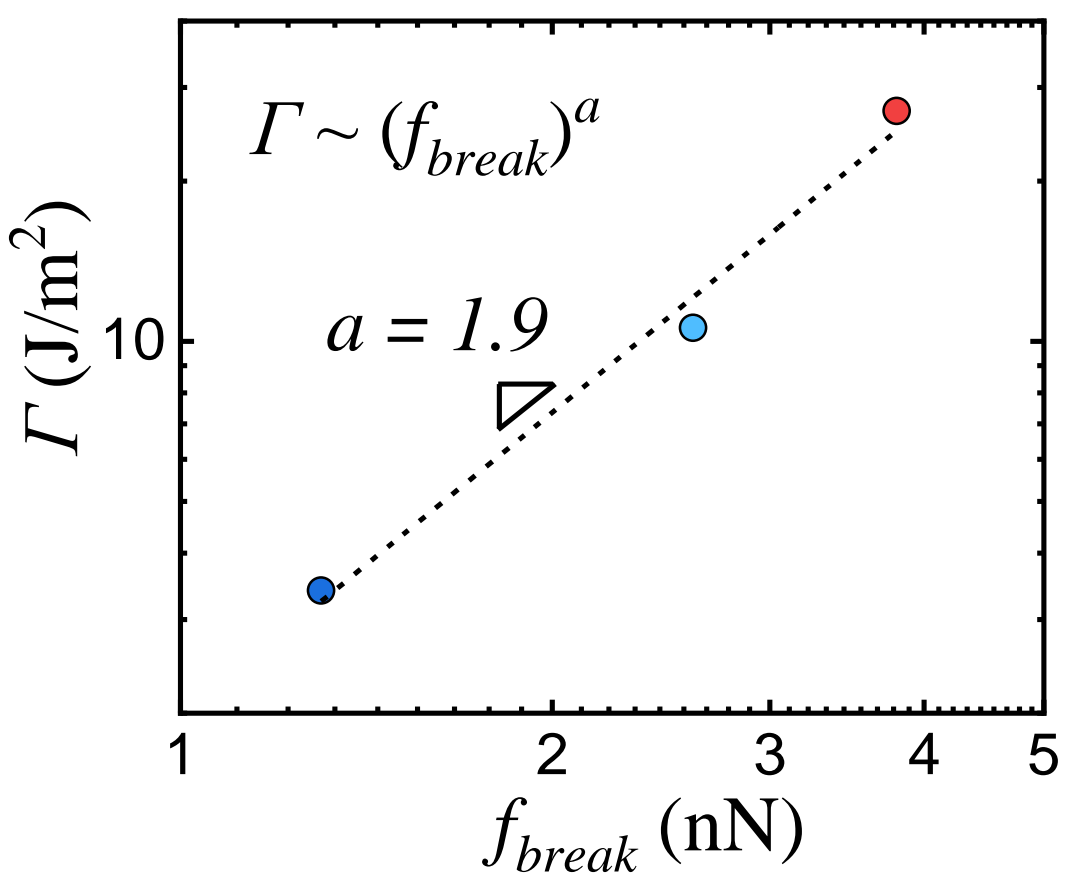

Figure S4. The tearing energies of Gels 1-3 versus the activation forces of Gels 1-3 at the loading rate of $10^{4} \mathrm{nN} / \mathrm{s}$ on log-log scale. The dashed line is the linear fitting of three data points. 


\section{NMR spectra}

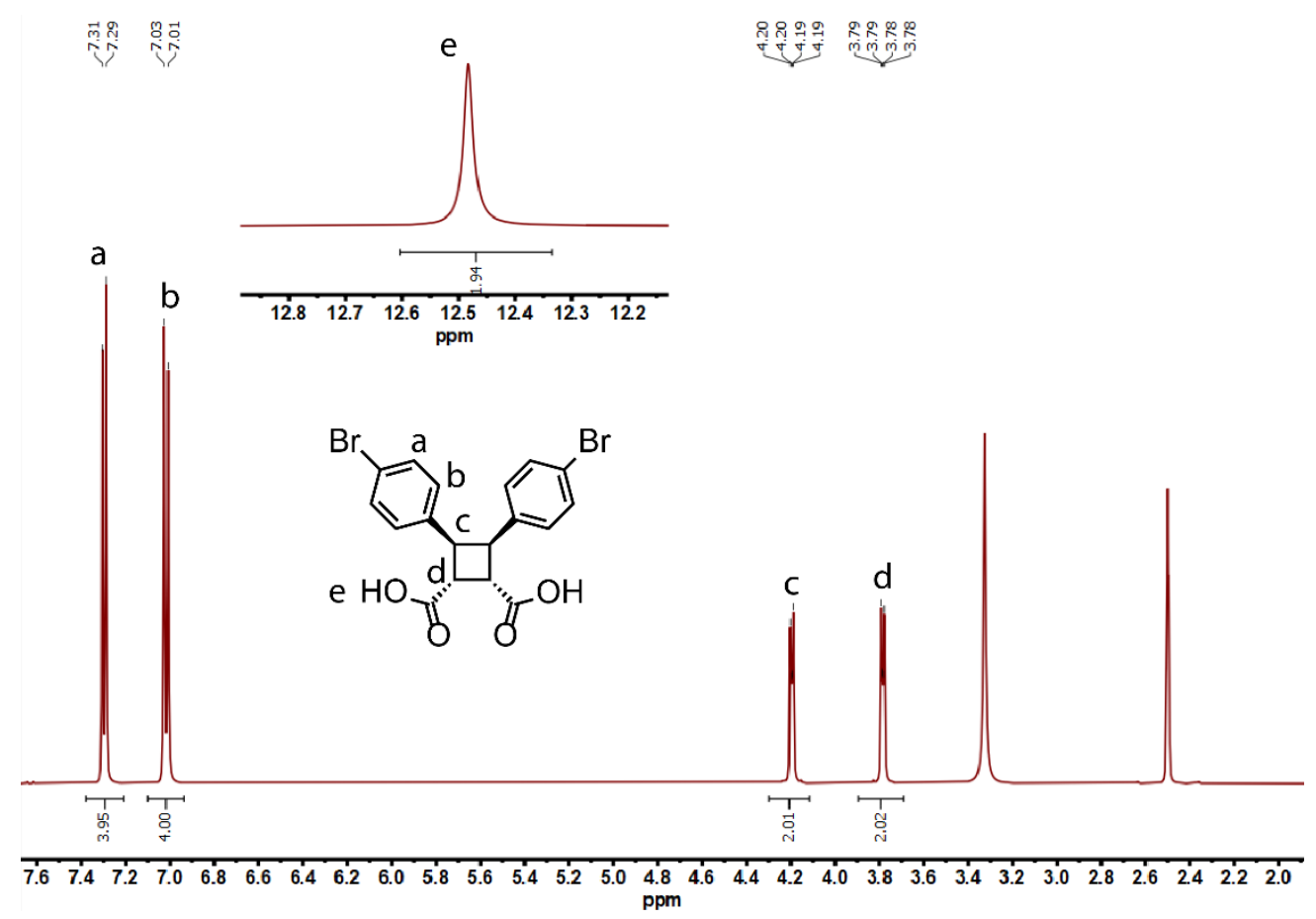

${ }^{1} \mathrm{H}$ NMR (500 MHz, DMSO-d6) spectrum of 1a
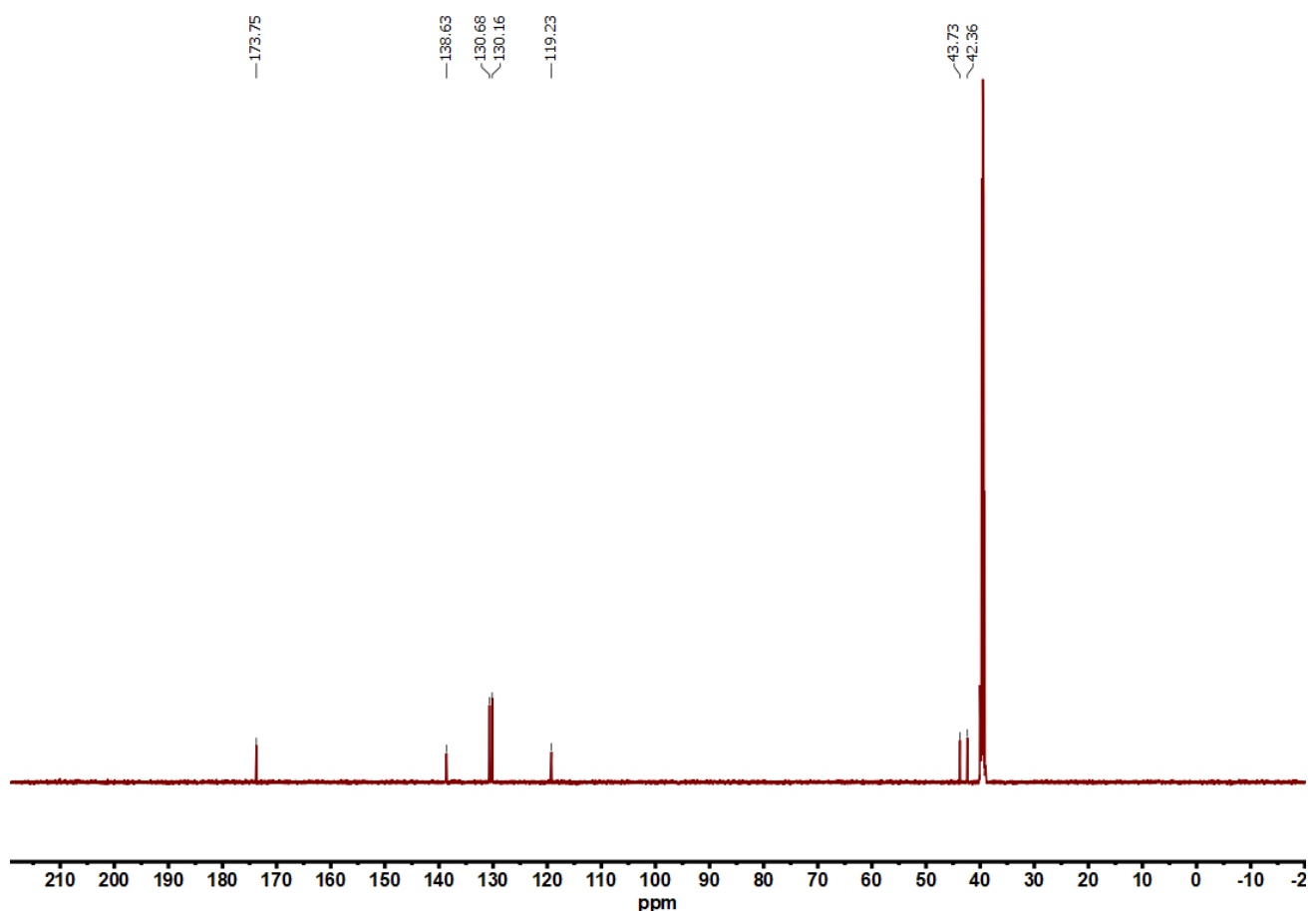

${ }^{13} \mathrm{C}$ NMR (125 MHz, DMSO-d6) spectrum of compound 1a 


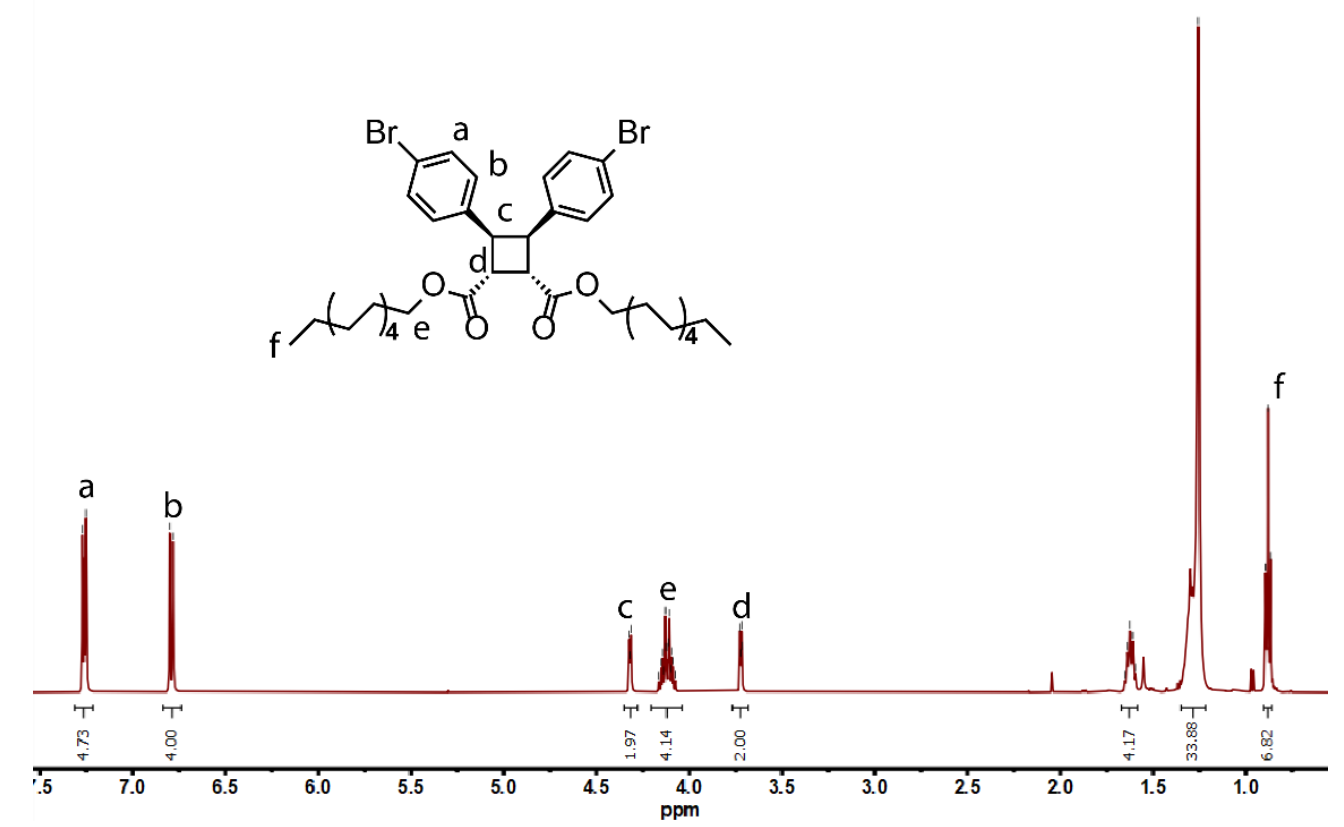

${ }^{1} \mathrm{H}$ NMR $\left(500 \mathrm{MHz}, \mathrm{CDCl}_{3}\right)$ spectrum of $\mathbf{1 b}$
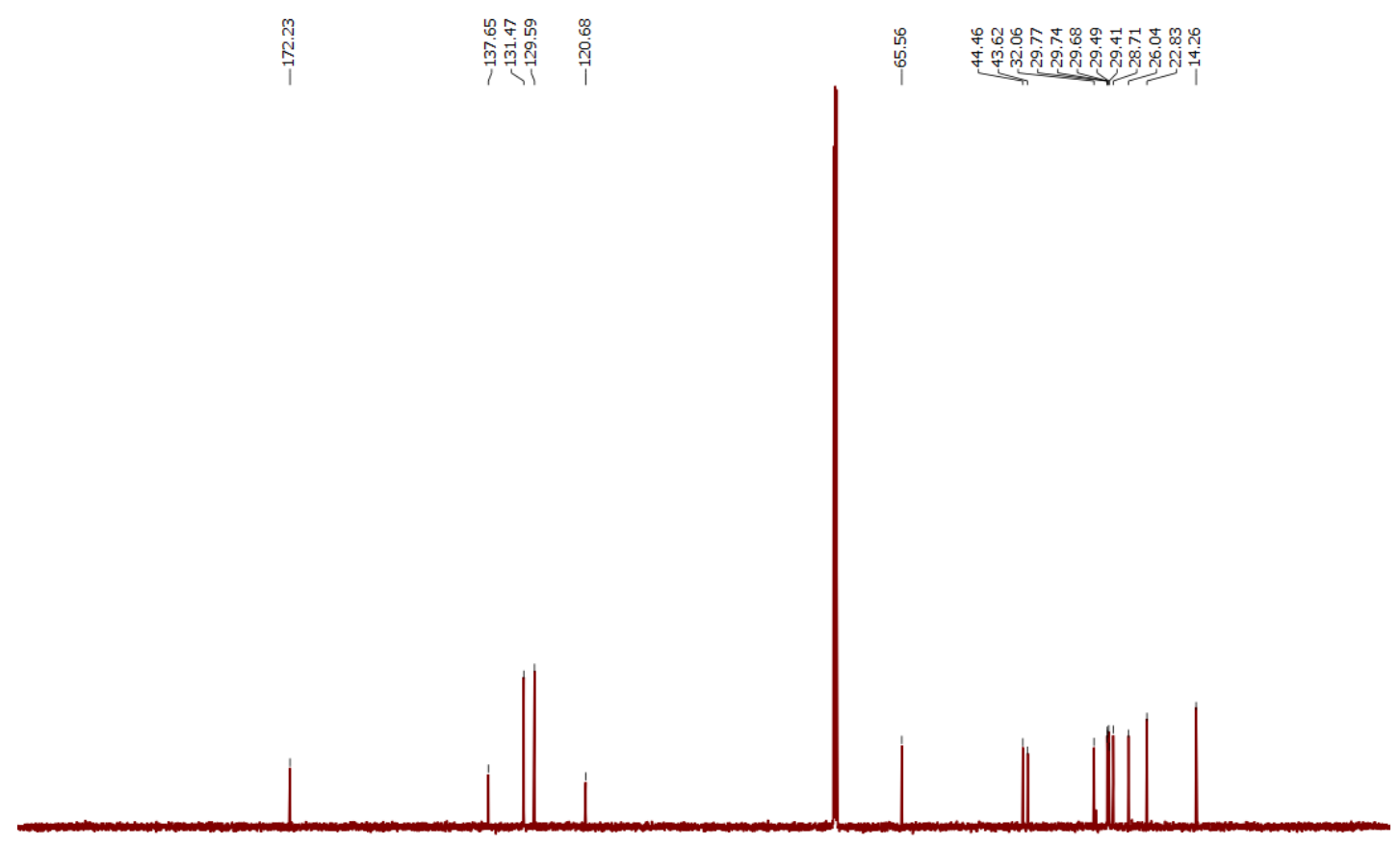

$\begin{array}{llllllllllllllllllllllll}210 & 200 & 190 & 180 & 170 & 160 & 150 & 140 & 130 & 120 & 110 & \begin{array}{l}100 \\ \mathrm{ppm}\end{array} & 90 & 80 & 70 & 60 & 50 & 40 & 30 & 20 & 10 & 0 & -10\end{array}$

${ }^{13} \mathrm{C} \mathrm{NMR}\left(125 \mathrm{MHz}, \mathrm{CDCl}_{3}\right)$ spectrum of compound $\mathbf{1 b}$ 

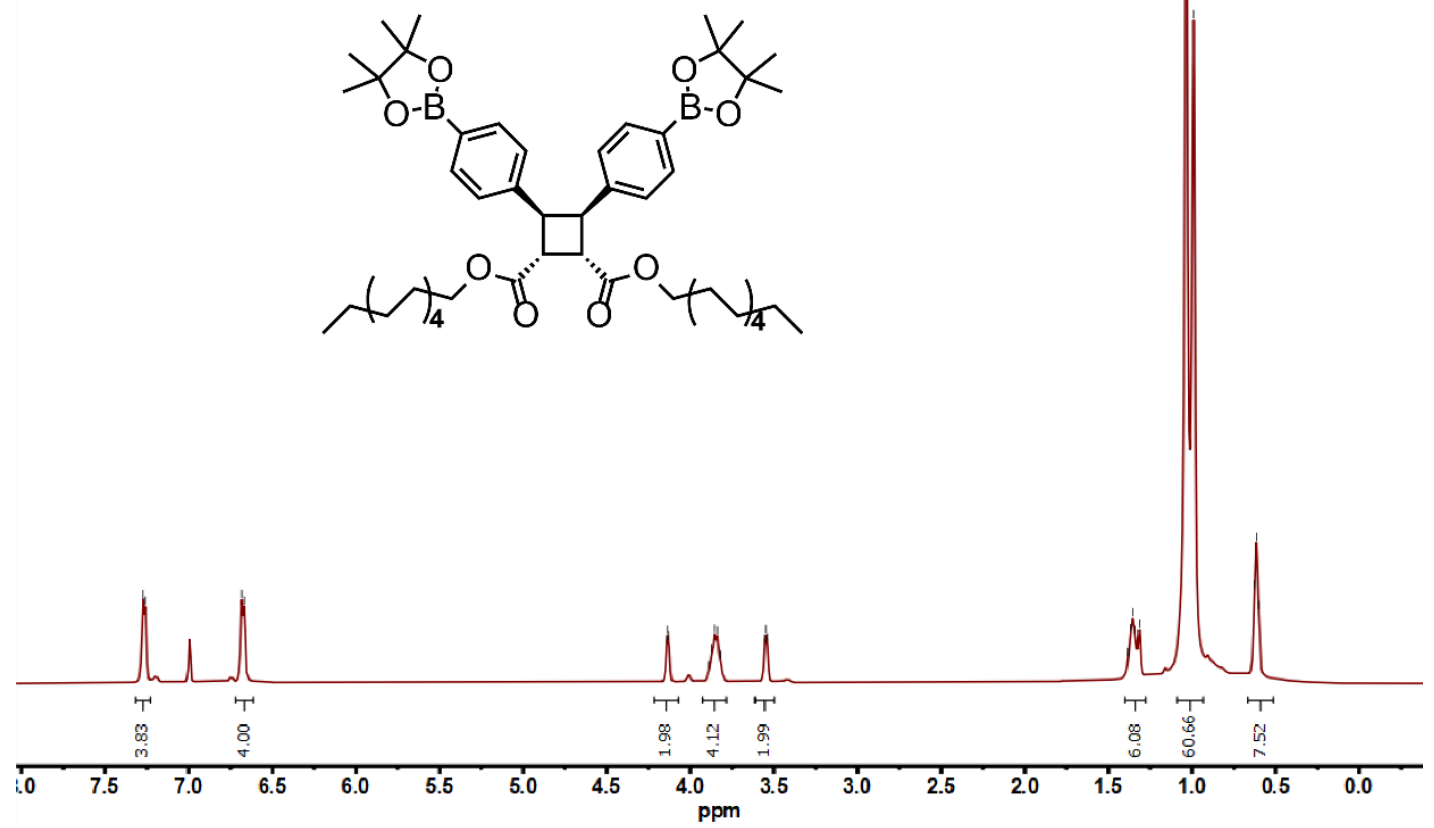

${ }^{1} \mathrm{H}$ NMR $\left(500 \mathrm{MHz}, \mathrm{CDCl}_{3}\right)$ spectrum of $\mathbf{1 c}$ with small amount of monofunctional byproduct.

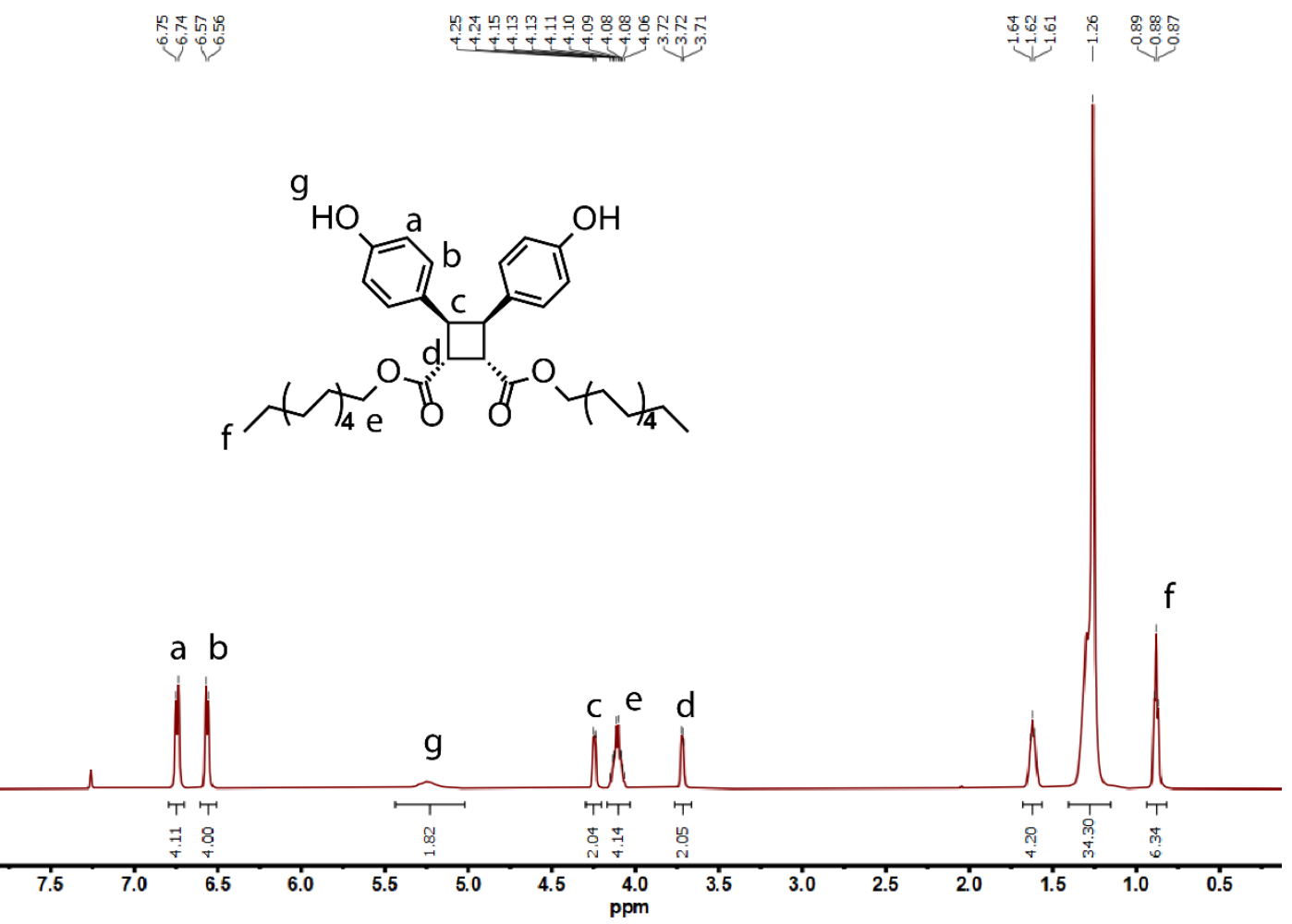

${ }^{1} \mathrm{H} \mathrm{NMR}\left(500 \mathrm{MHz}, \mathrm{CDCl}_{3}\right)$ spectrum of $\mathbf{1 d}$ 

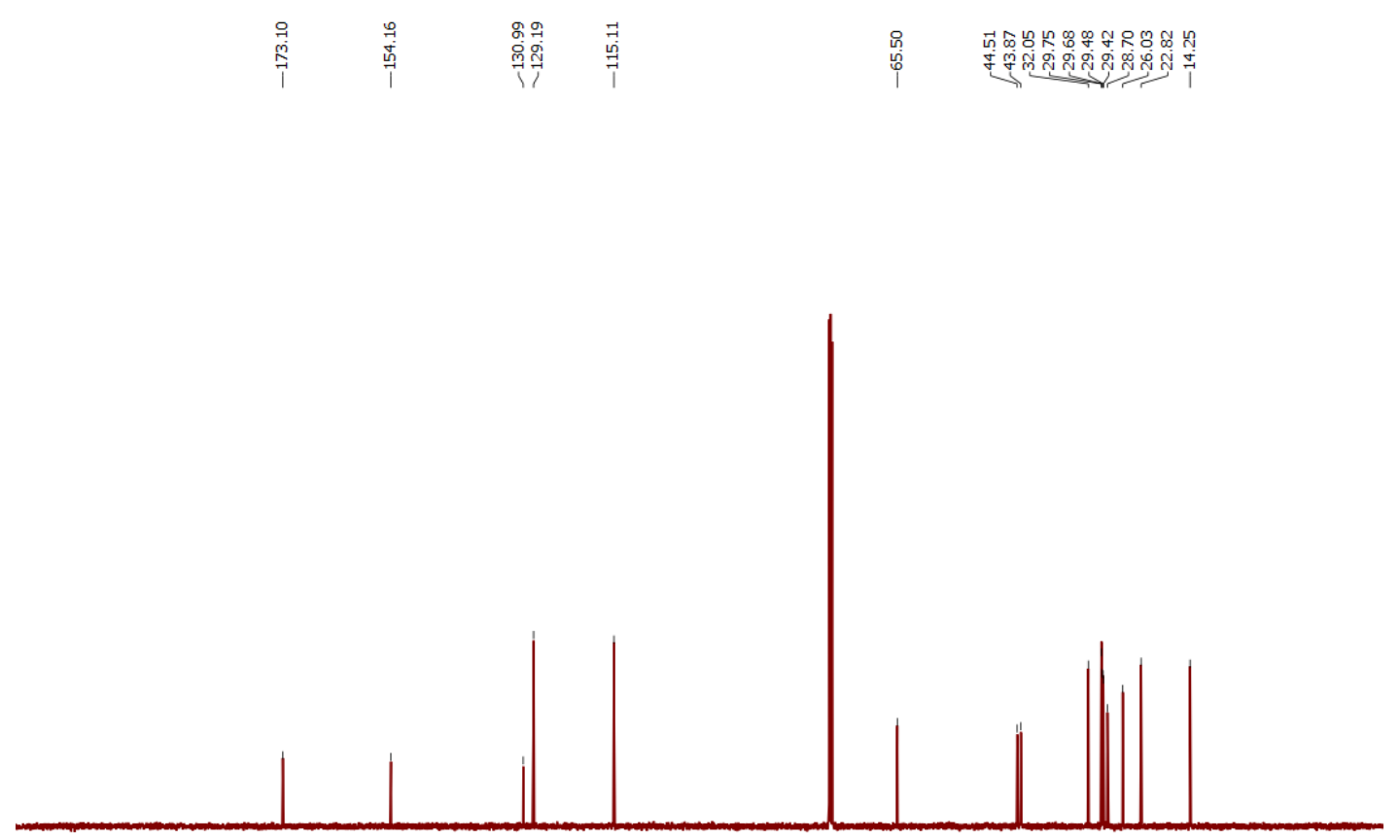

\begin{tabular}{lllllllllllllllllllllll}
\hline 210 & 200 & 190 & 180 & 170 & 160 & 150 & 140 & 130 & 120 & 110 & $\begin{array}{c}100 \\
\mathrm{ppm}\end{array}$ & 90 & 80 & 70 & 60 & 50 & 40 & 30 & 20 & 10 & 0 & -10
\end{tabular}

${ }^{13} \mathrm{C}$ NMR $\left(125 \mathrm{MHz}, \mathrm{CDCl}_{3}\right)$ spectrum of compound $\mathbf{1 d}$

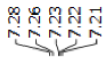

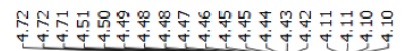
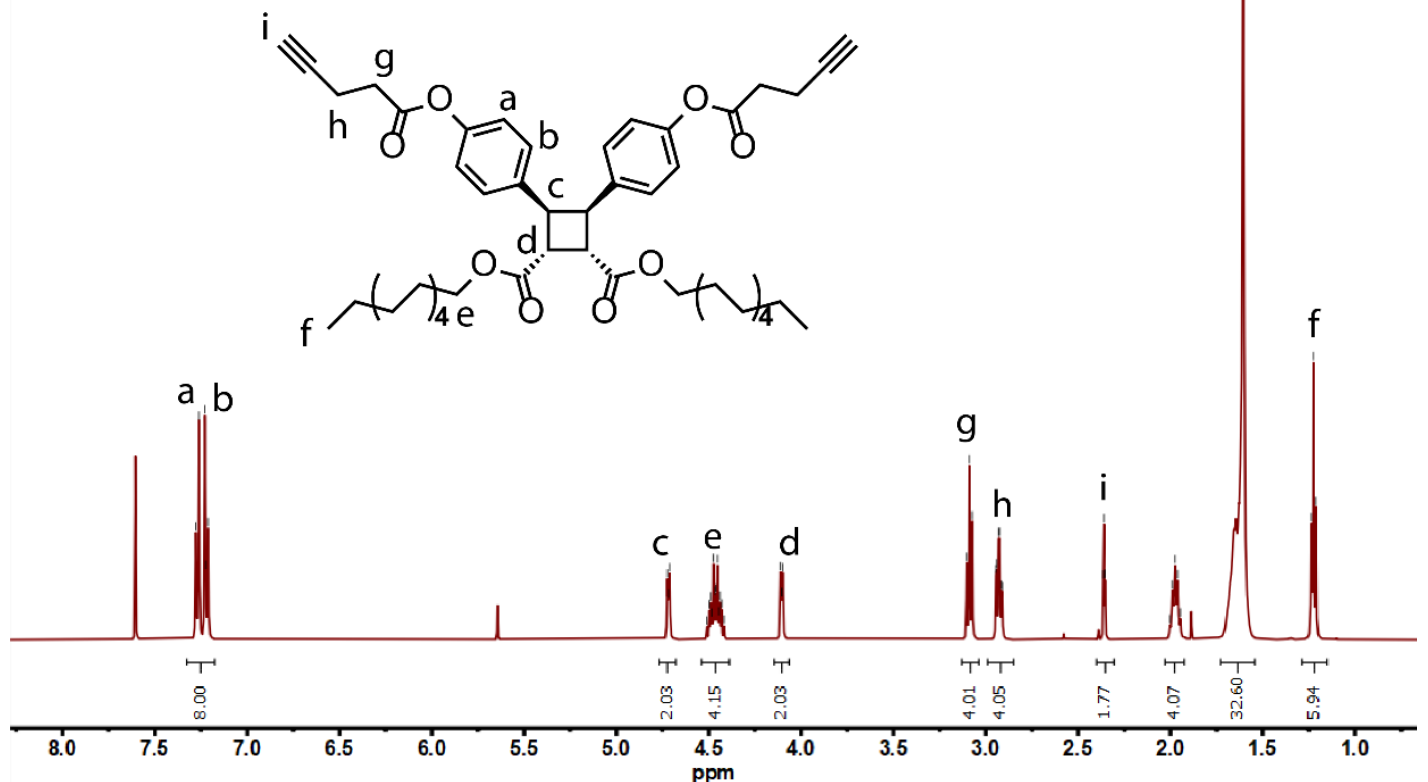

${ }^{1} \mathrm{H}$ NMR (400 MHz, $\mathrm{CDCl}_{3}$ ) spectrum of $\mathbf{1}$ 

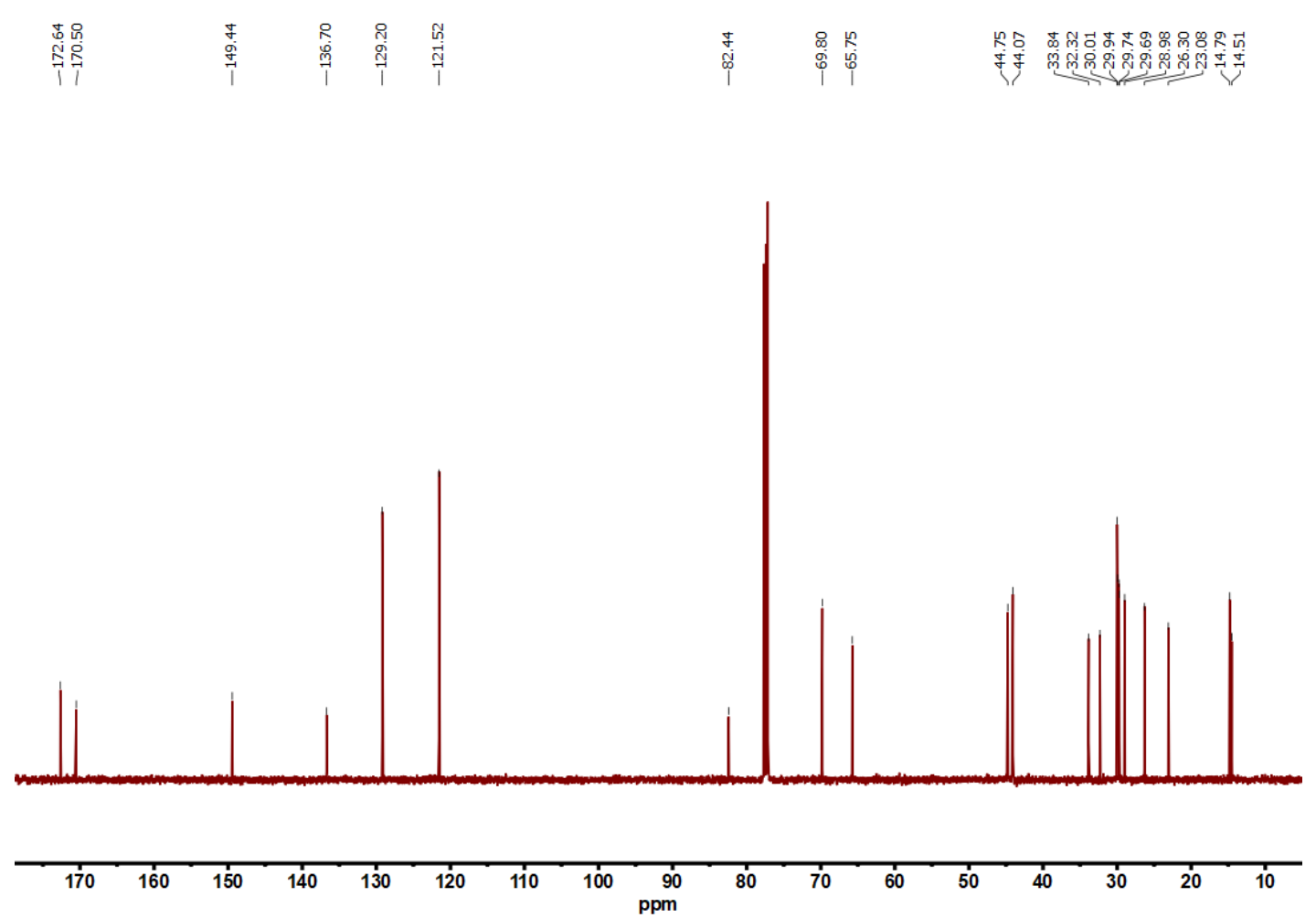

${ }^{13} \mathrm{C}$ NMR $\left(100 \mathrm{MHz}, \mathrm{CDCl}_{3}\right)$ spectrum of $\mathbf{1}$
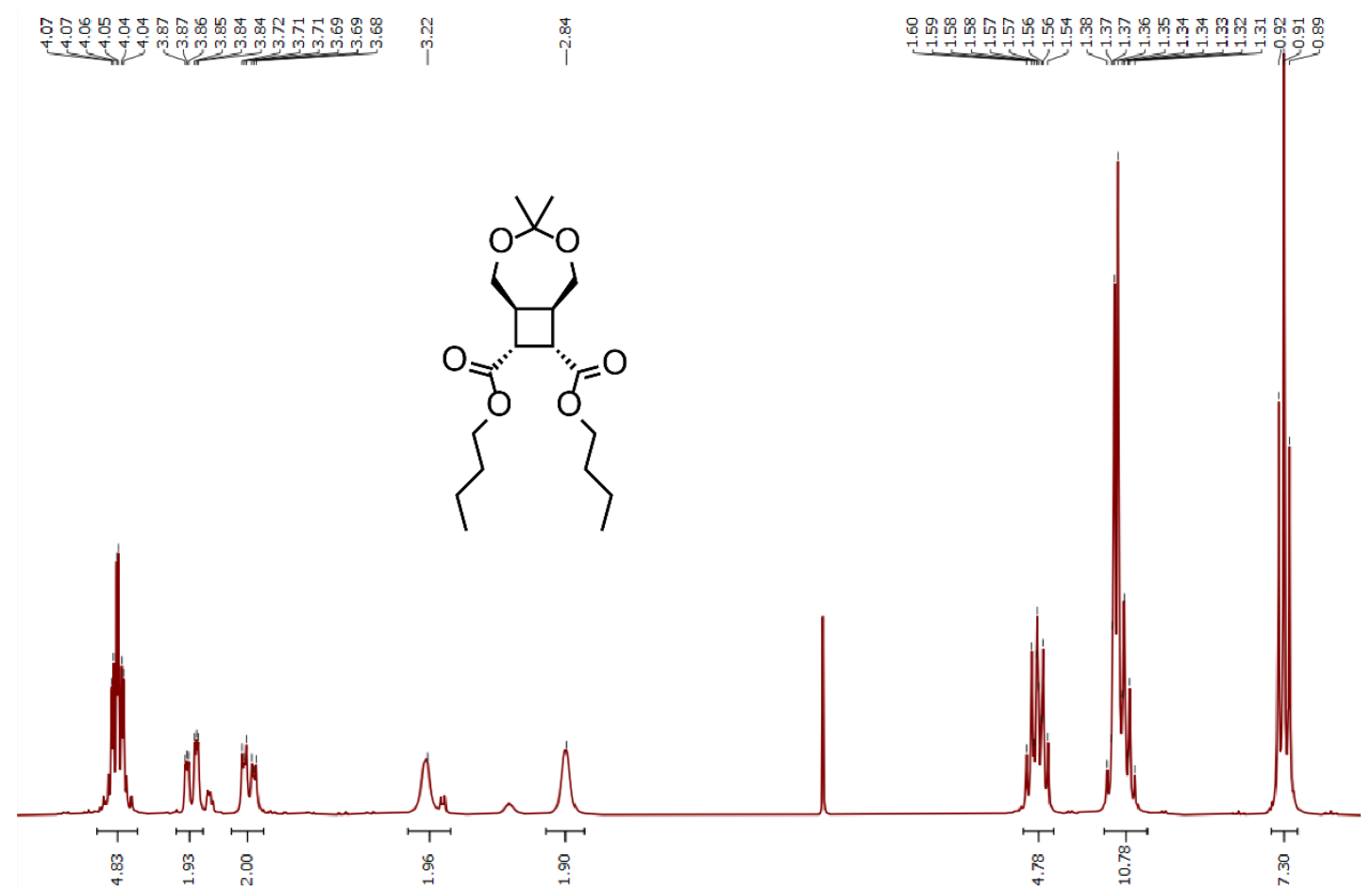

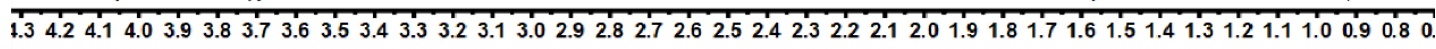
$\mathrm{ppm}$

${ }^{1} \mathrm{H}$ NMR $\left(500 \mathrm{MHz}, \mathrm{CDCl}_{3}\right)$ spectrum of $\mathbf{2 b}$ 


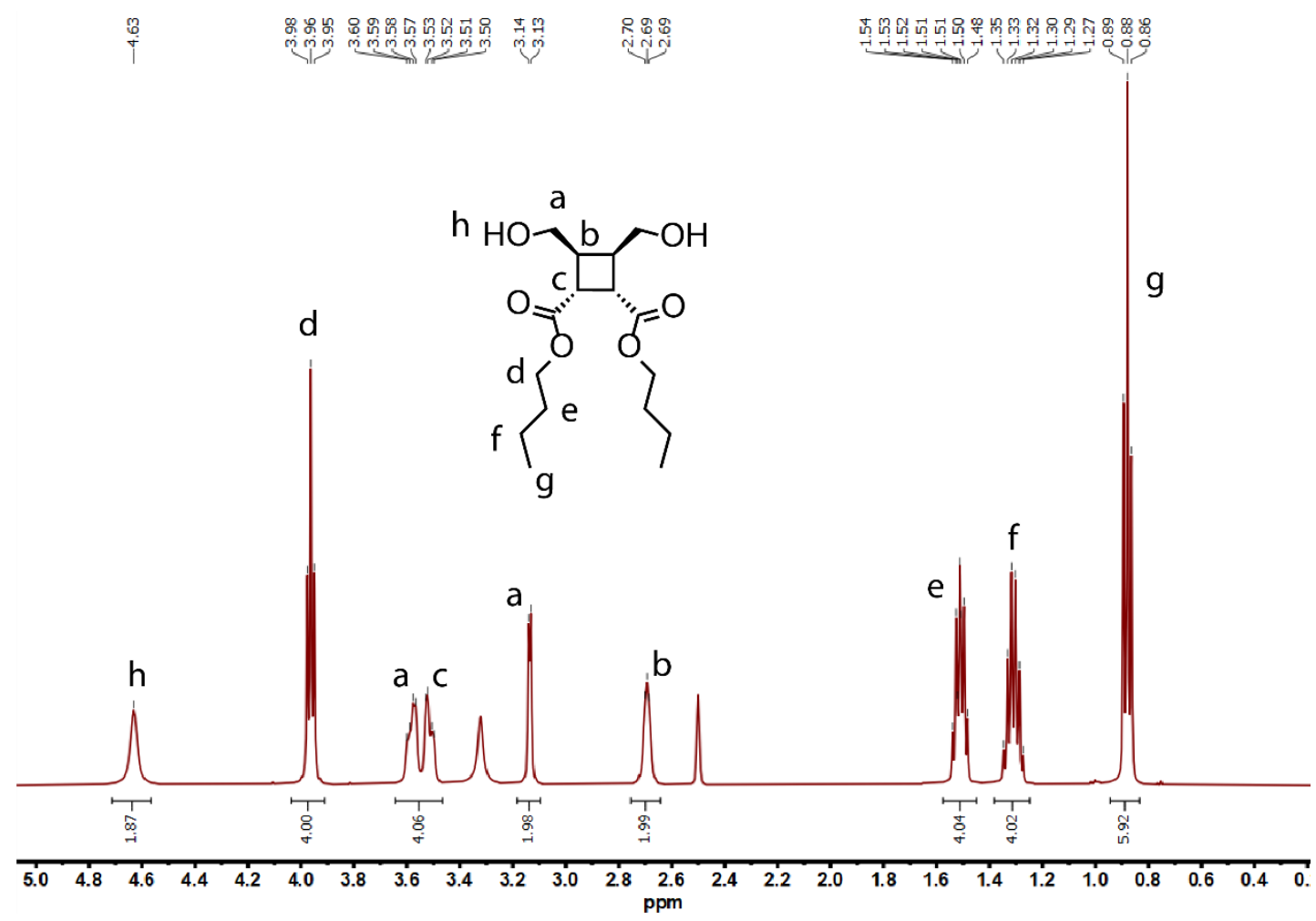

${ }^{1} \mathrm{H}$ NMR (500 MHz, DMSO-d6) spectrum of 2c
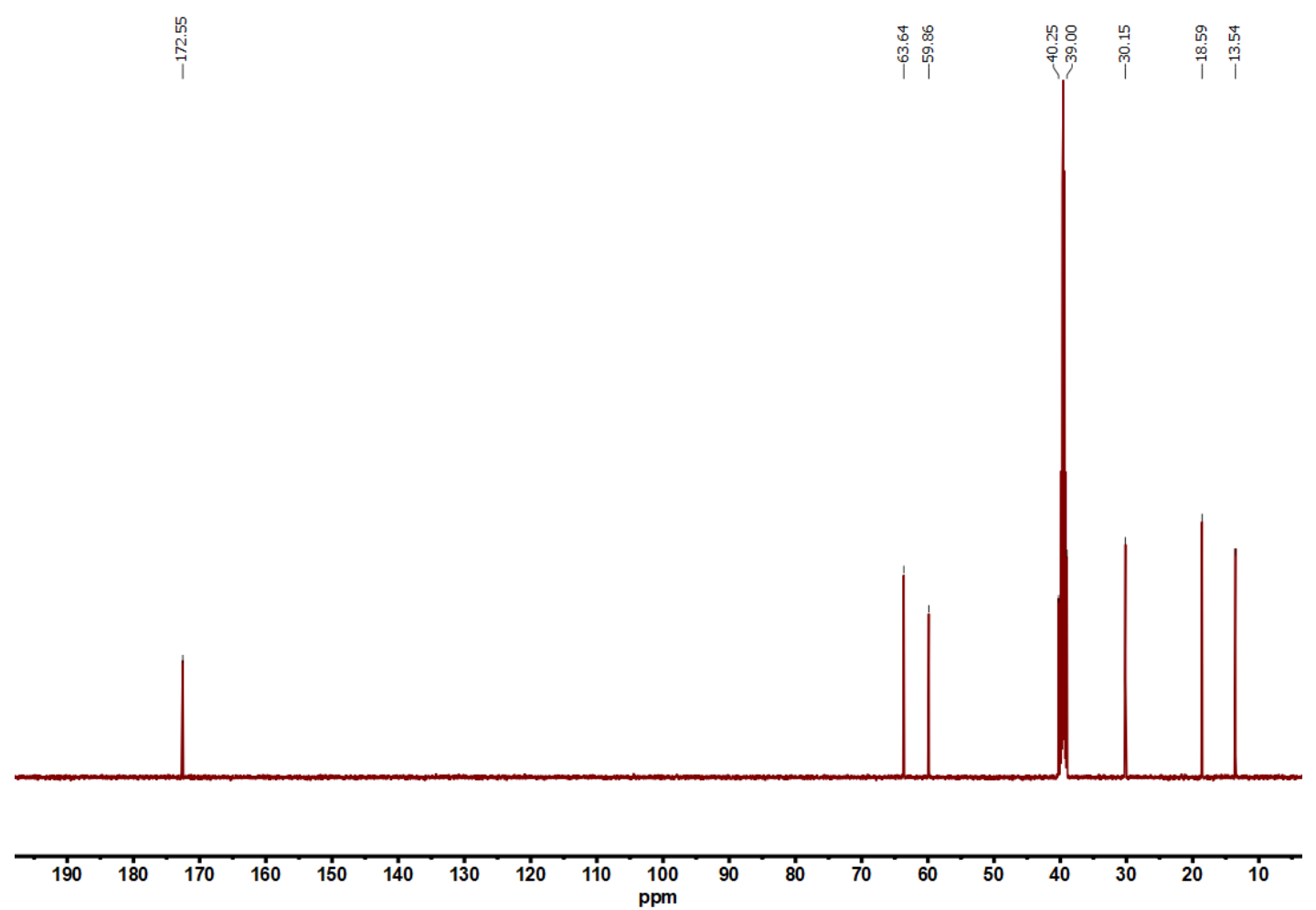

${ }^{13} \mathrm{C}$ NMR (125 MHz, DMSO-d6) spectrum of compound 2c 

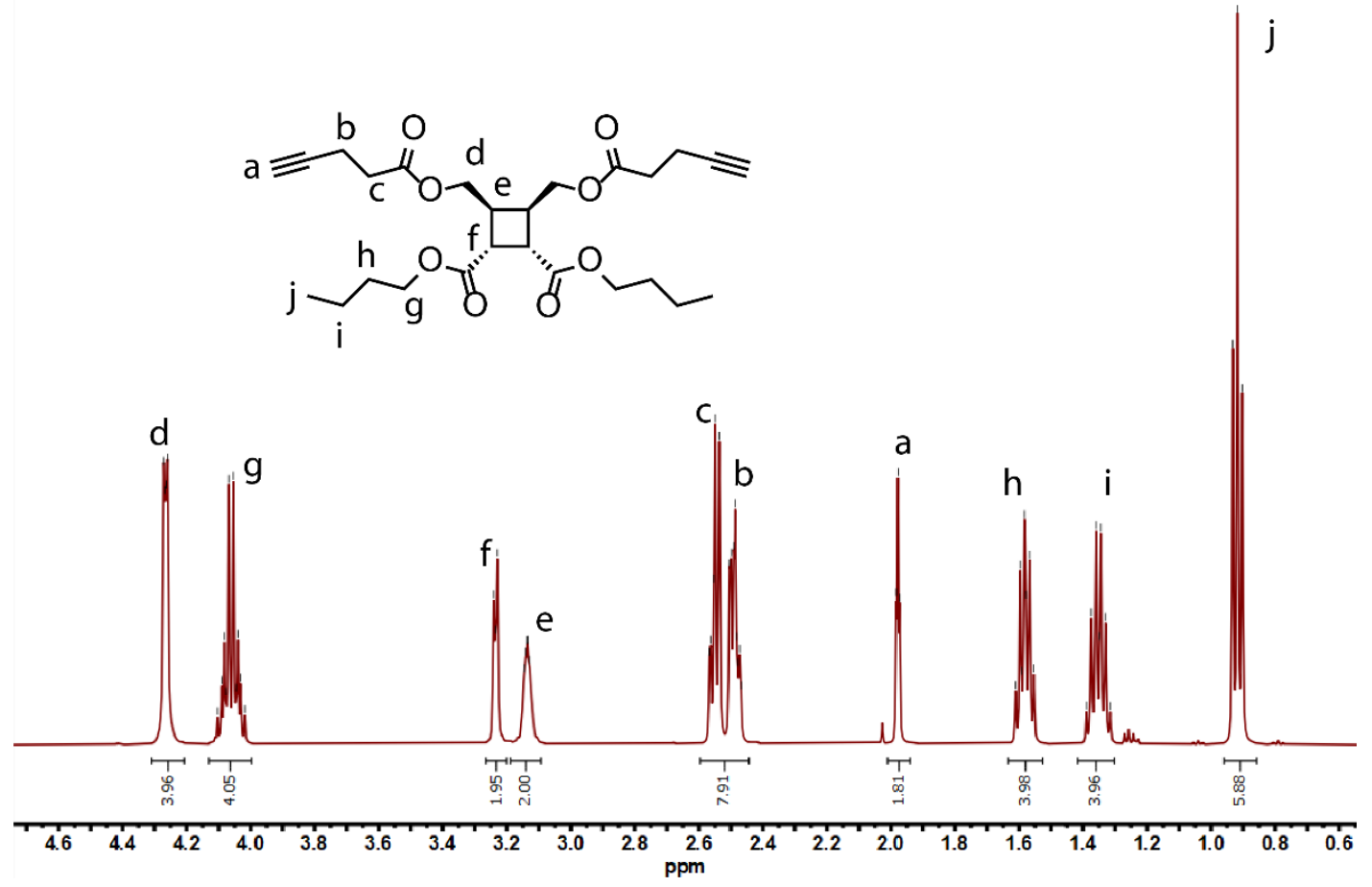

${ }^{1} \mathrm{H}$ NMR $\left(500 \mathrm{MHz}, \mathrm{CDCl}_{3}\right)$ spectrum of 2

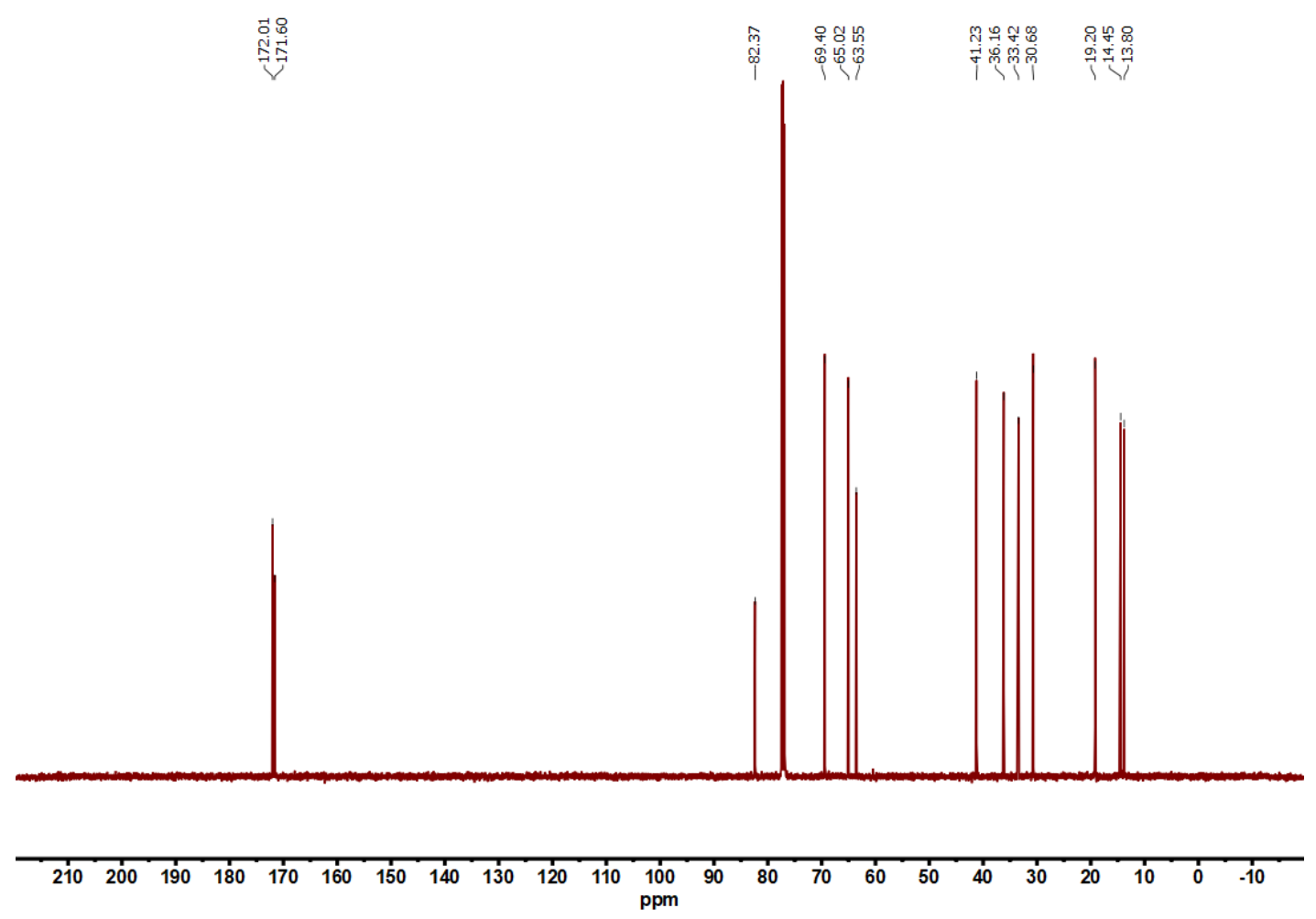

${ }^{13} \mathrm{C}$ NMR $\left(125 \mathrm{MHz}, \mathrm{CDCl}_{3}\right)$ spectrum of compound 2 


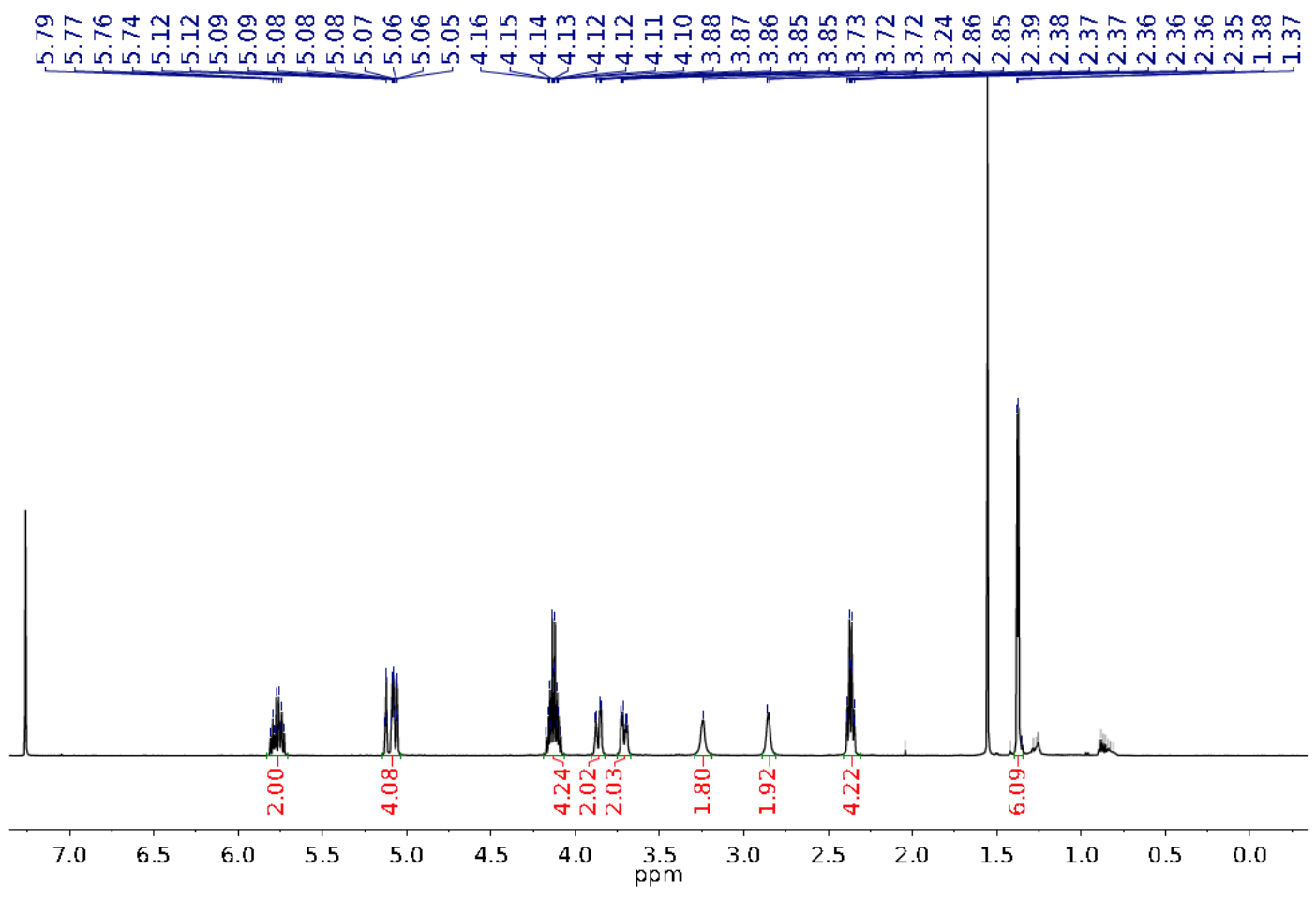

${ }^{1} \mathrm{H}$ NMR $\left(500 \mathrm{MHz}, \mathrm{CDCl}_{3}\right)$ spectrum of IIb

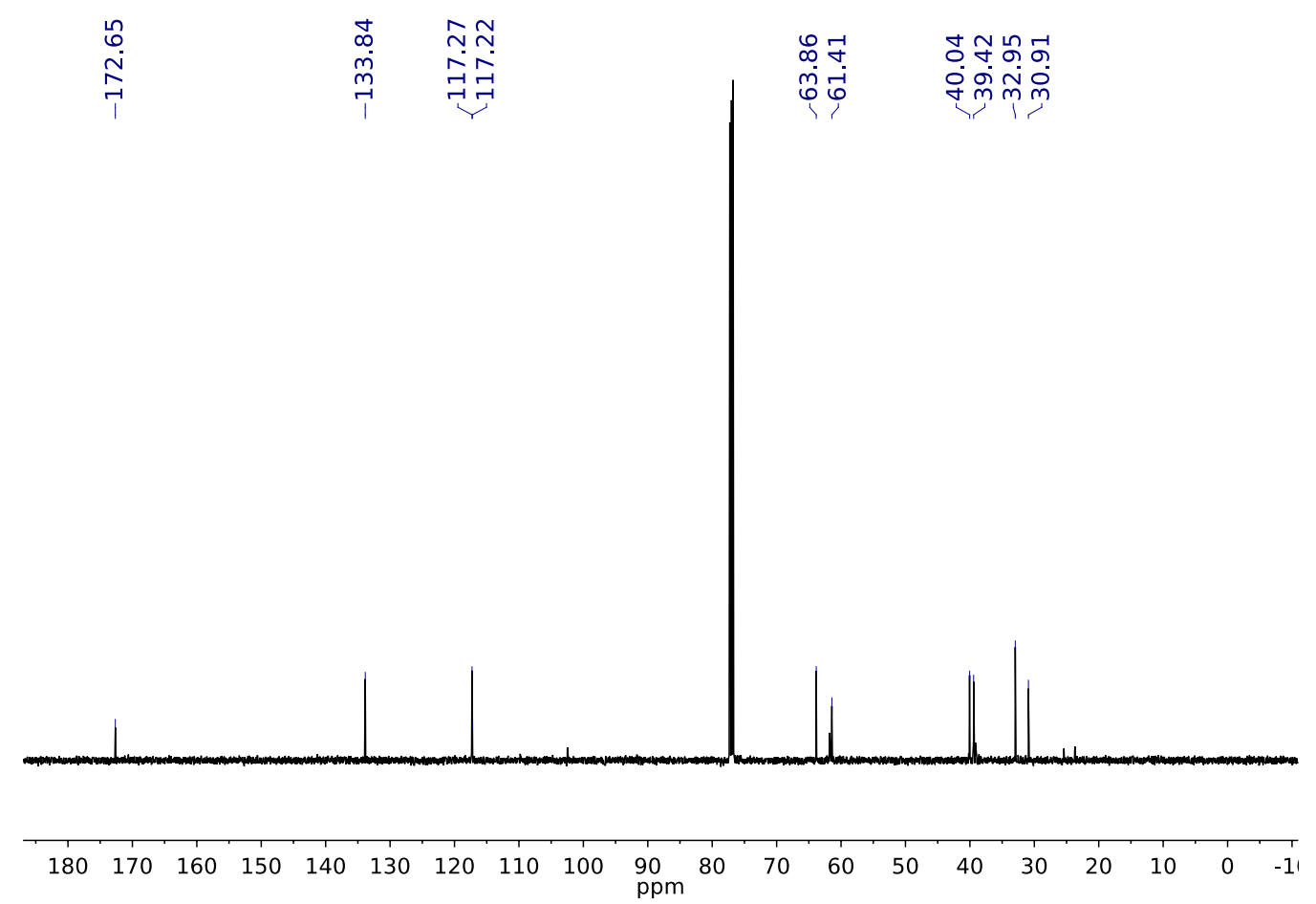

${ }^{13} \mathrm{C}$ NMR $\left(125 \mathrm{MHz}, \mathrm{CDCl}_{3}\right)$ spectrum of $\mathbf{I I b}$ 


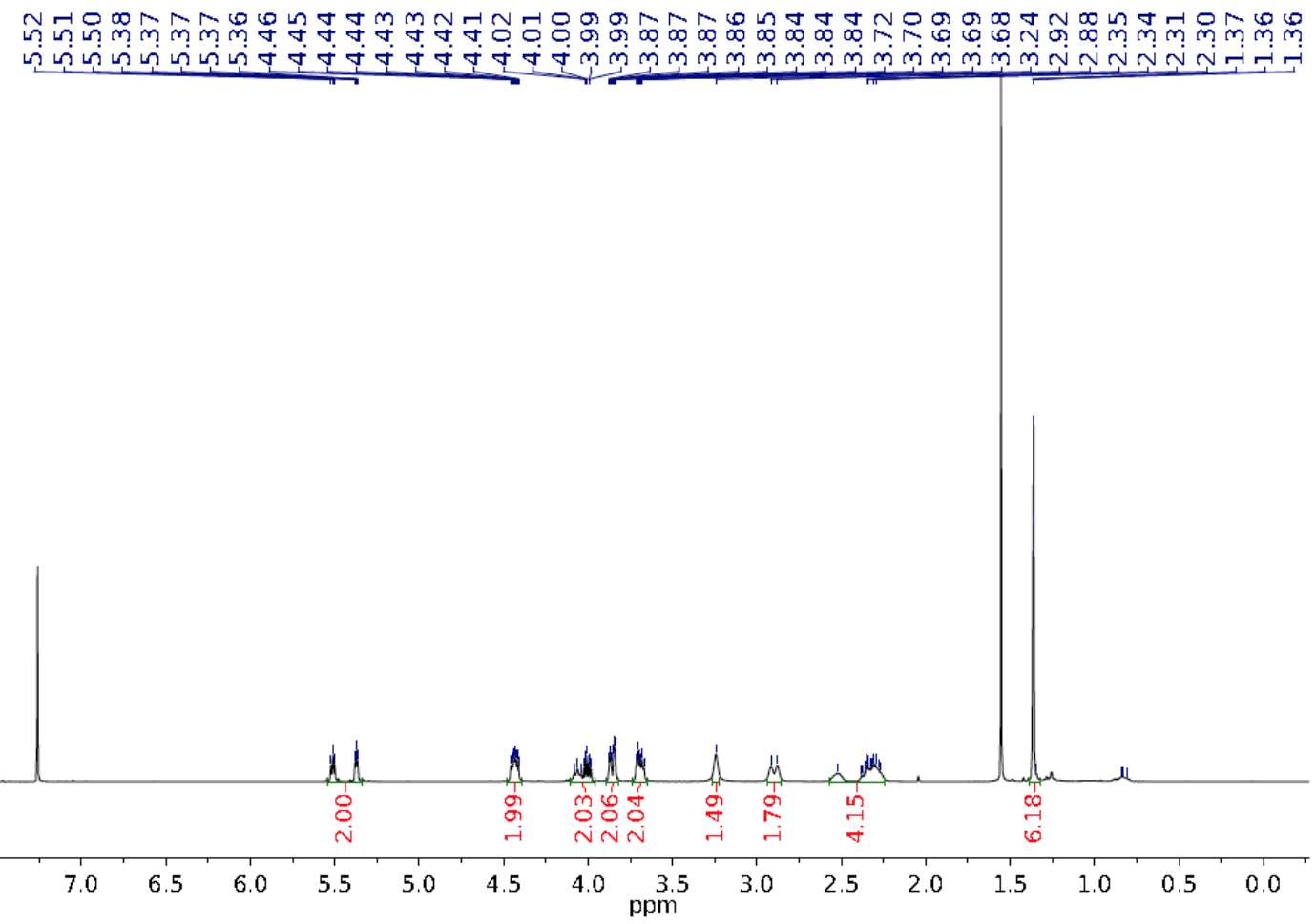

${ }^{1} \mathrm{H}$ NMR (500 MHz, $\left.\mathrm{CDCl}_{3}\right)$ spectrum of IIc

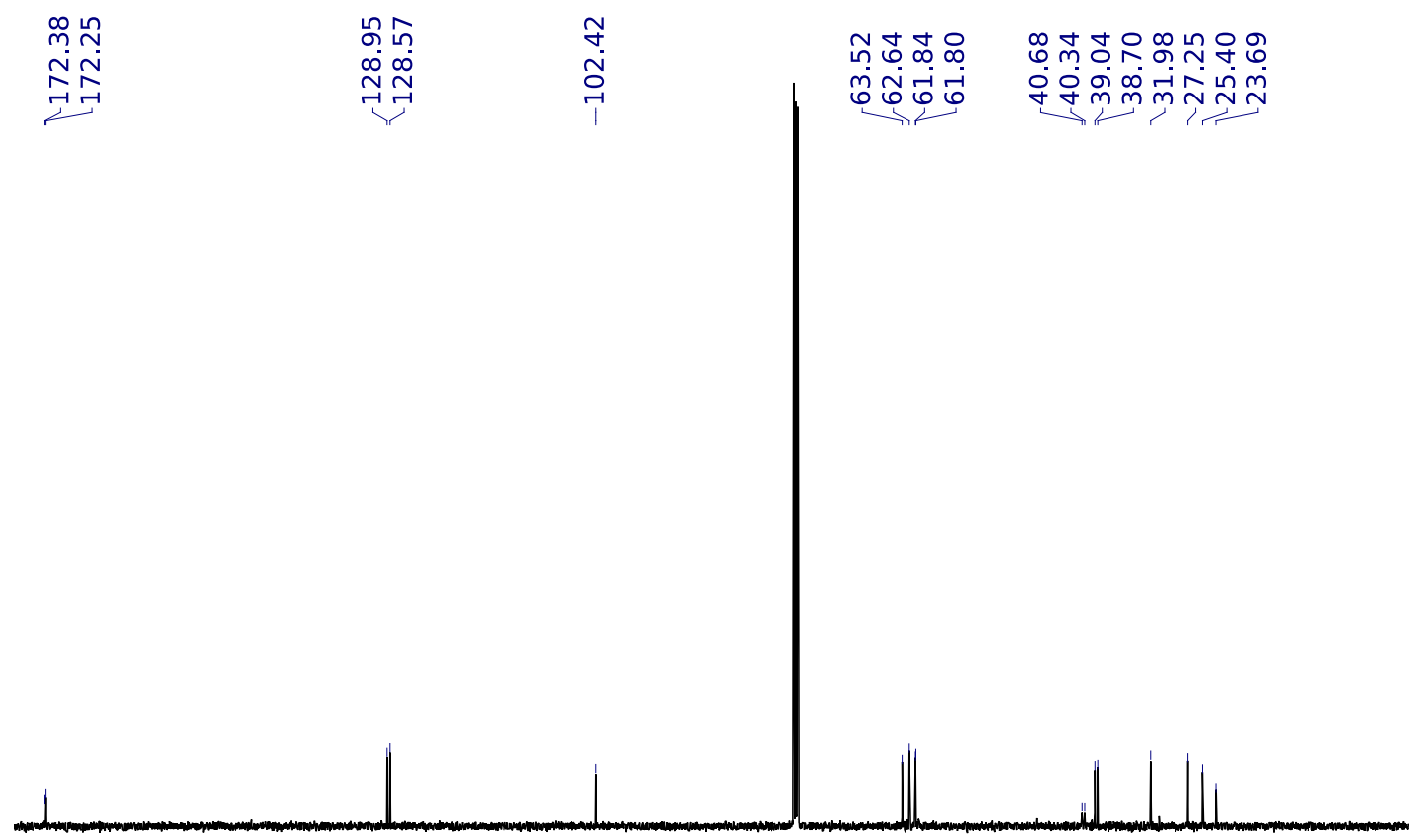

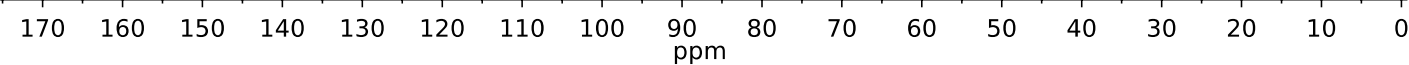

${ }^{13} \mathrm{C}$ NMR $\left(125 \mathrm{MHz}, \mathrm{CDCl}_{3}\right)$ spectrum of IIc 


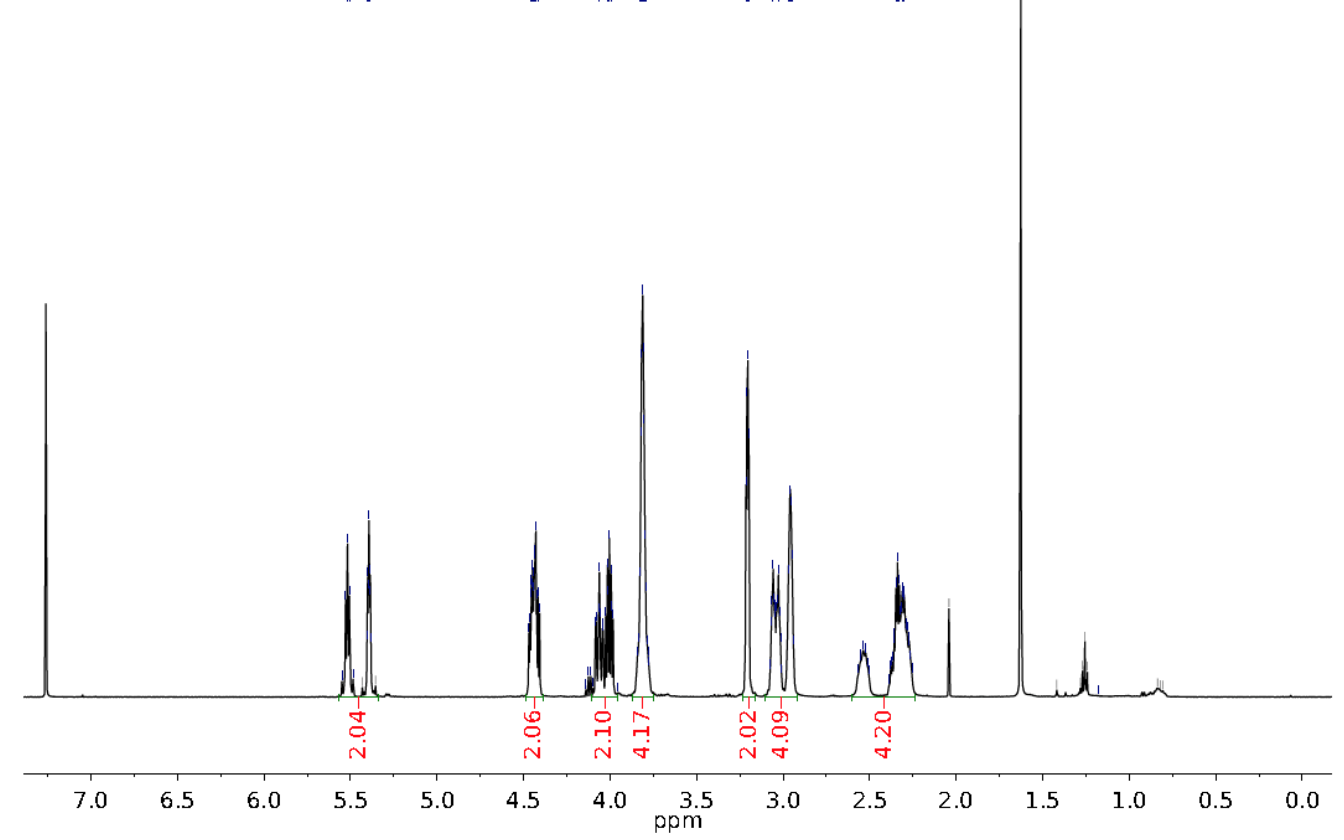

${ }^{1} \mathrm{H}$ NMR $\left(500 \mathrm{MHz}, \mathrm{CDCl}_{3}\right)$ spectrum of IId

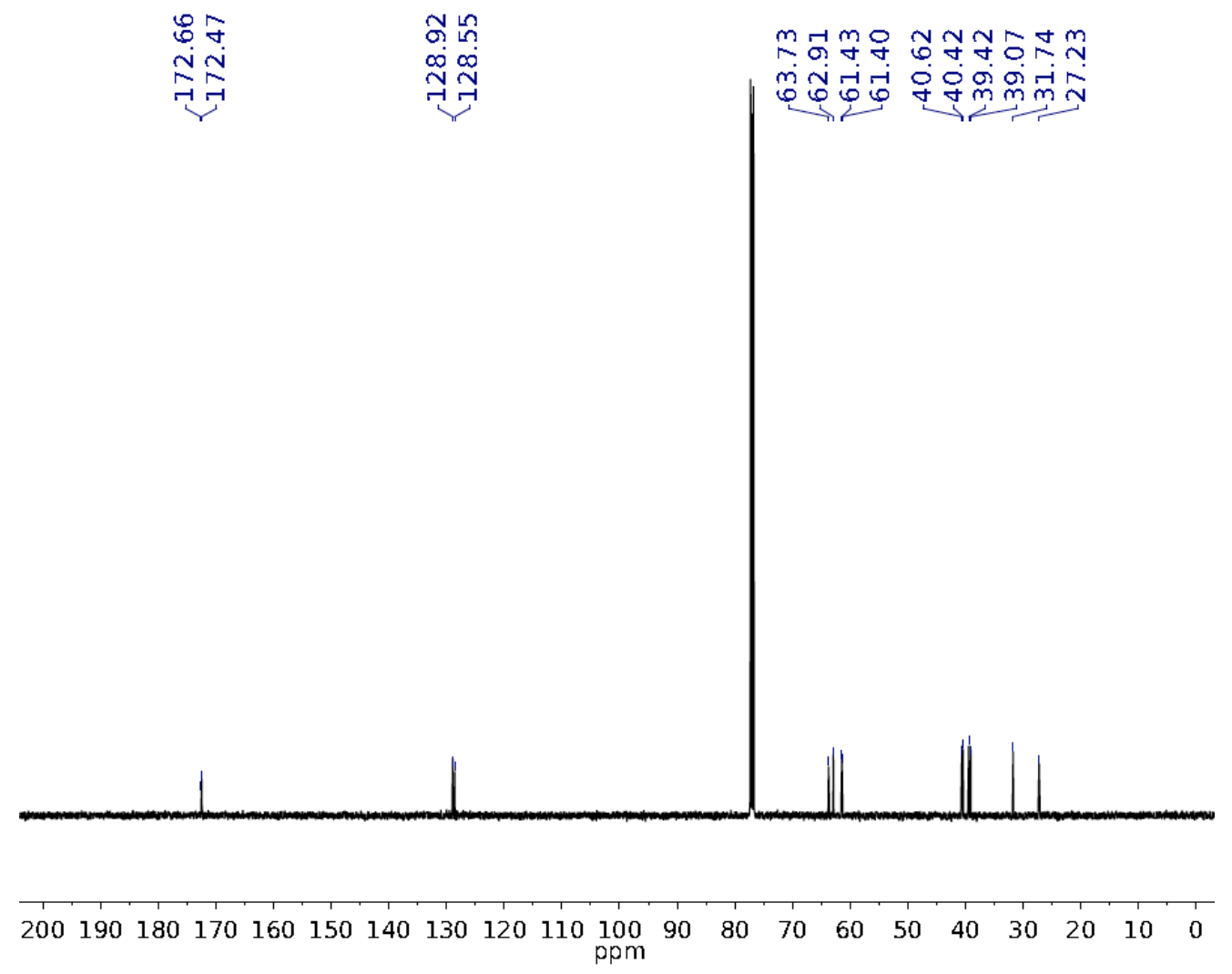

${ }^{13} \mathrm{C}$ NMR $\left(125 \mathrm{MHz}, \mathrm{CDCl}_{3}\right)$ spectrum of IId 


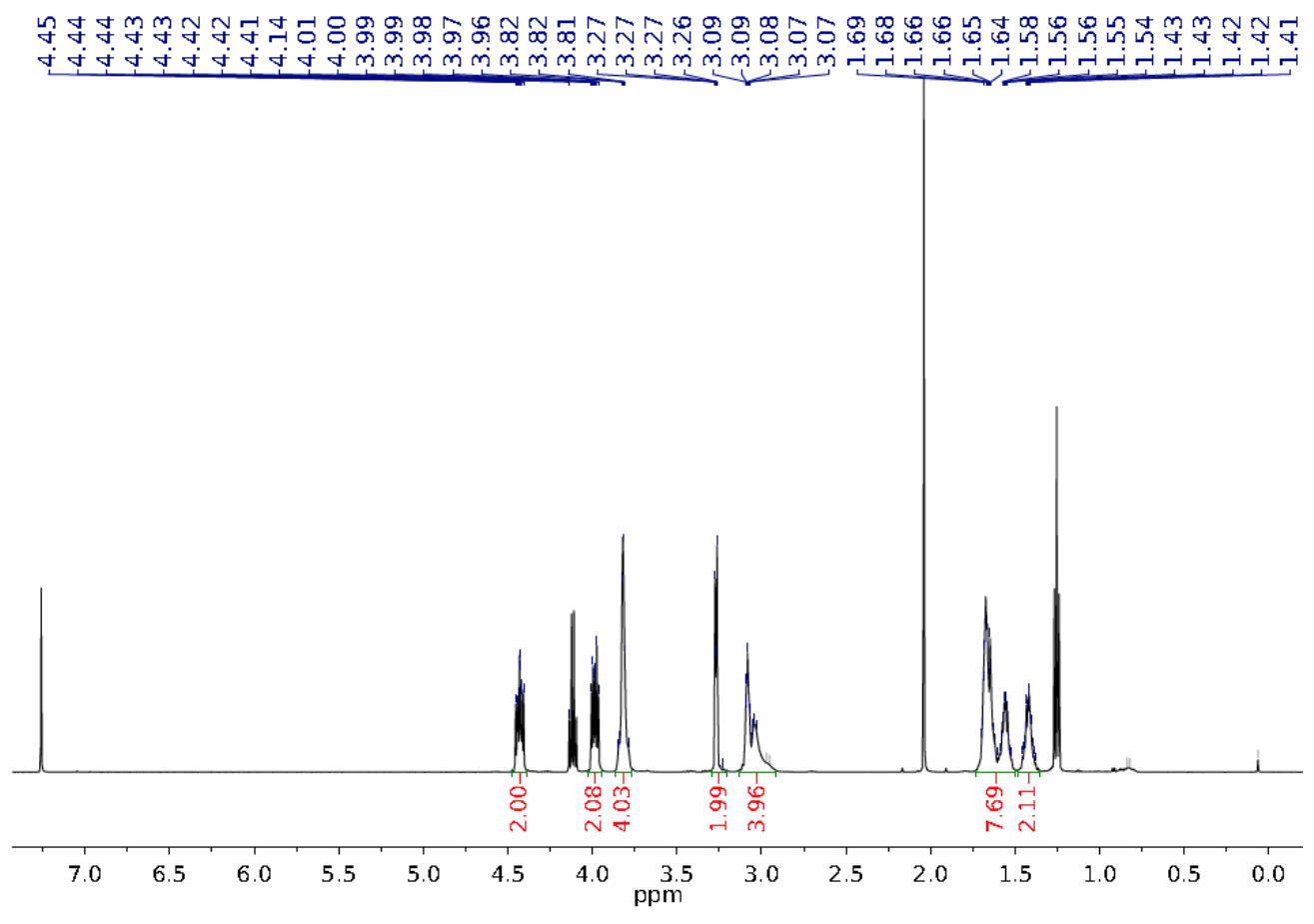

${ }^{1} \mathrm{H}$ NMR $\left(500 \mathrm{MHz}, \mathrm{CDCl}_{3}\right.$ ) spectrum of IIe
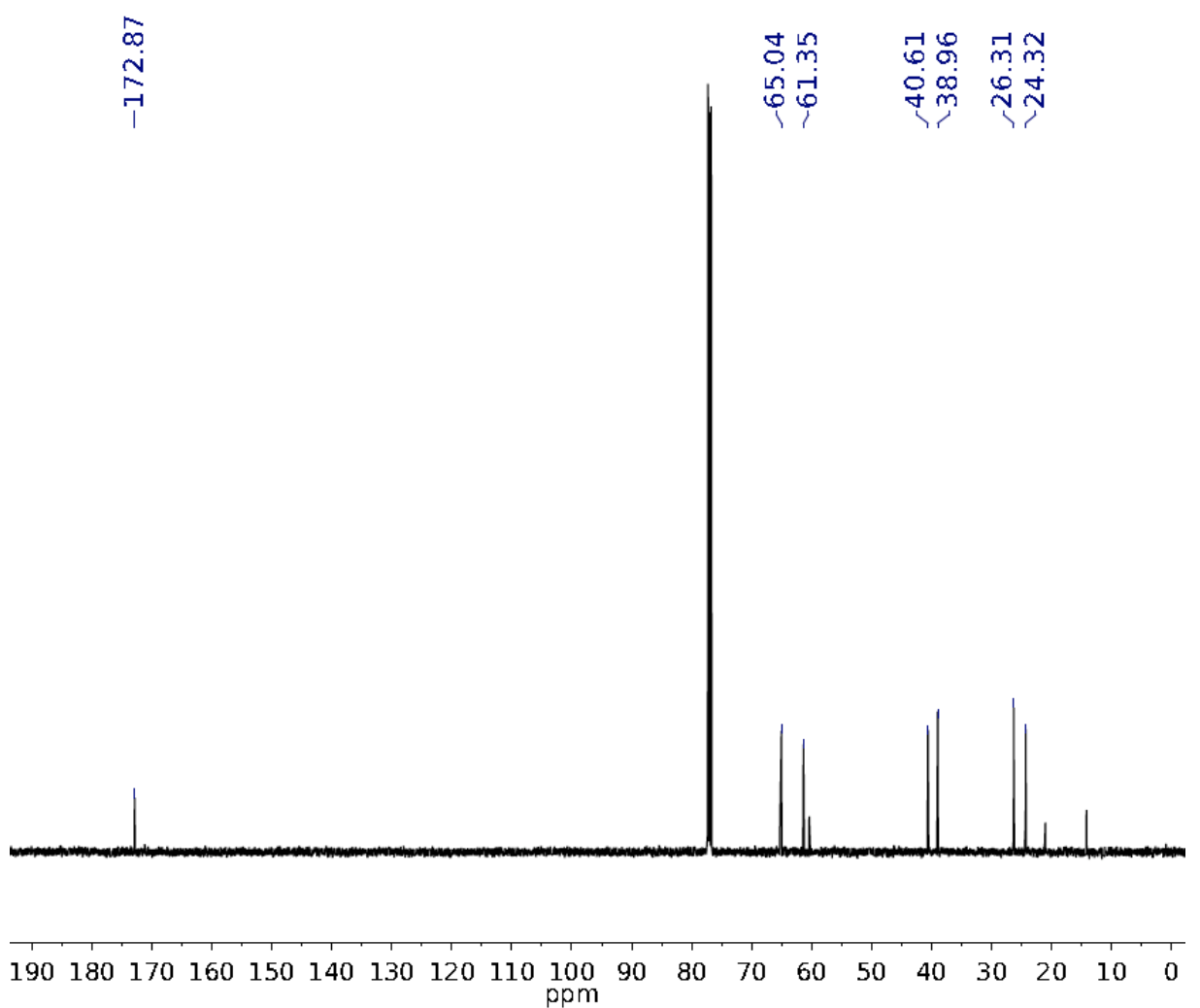

${ }^{13} \mathrm{C} \mathrm{NMR}\left(125 \mathrm{MHz}, \mathrm{CDCl}_{3}\right)$ spectrum of IIe 


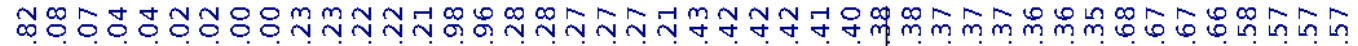
மn்

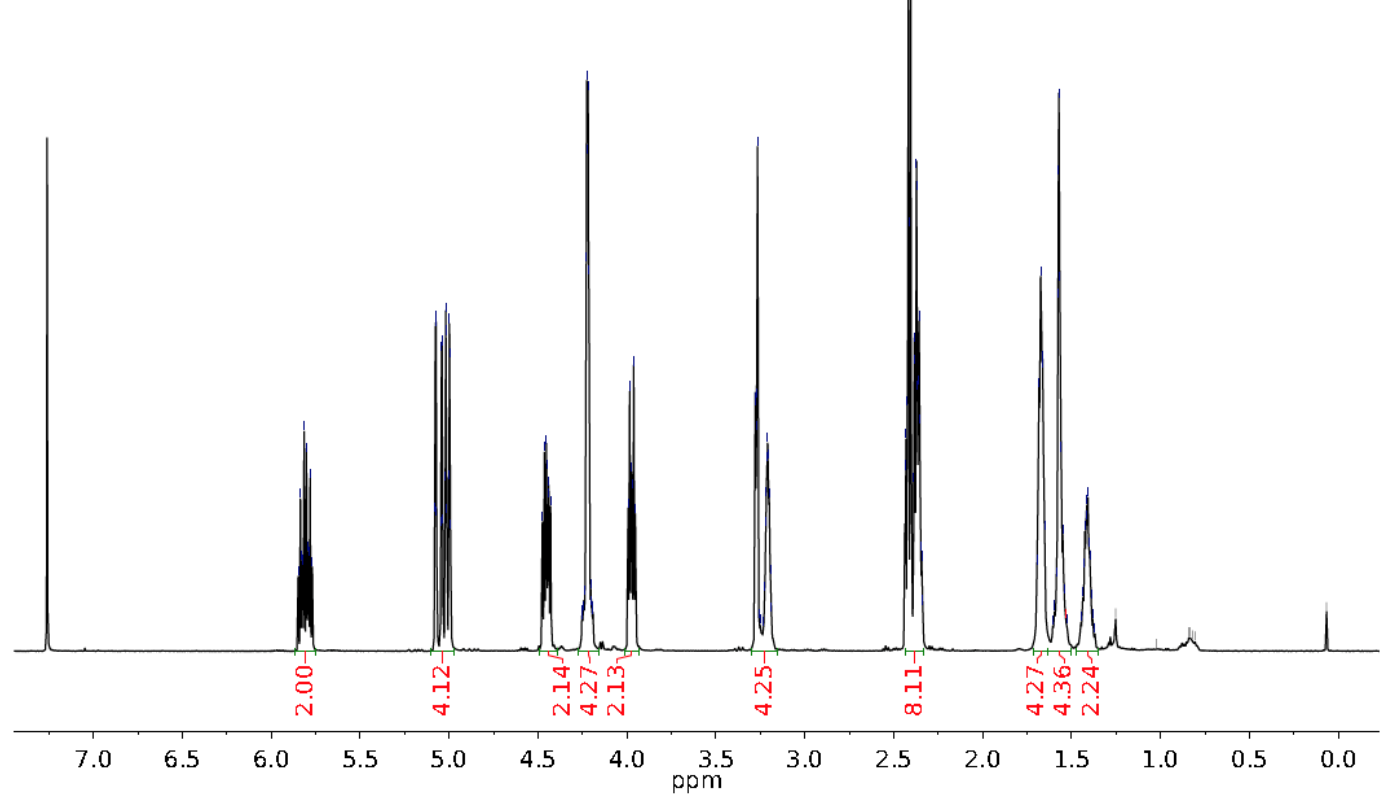

${ }^{1} \mathrm{H}$ NMR $\left(500 \mathrm{MHz}, \mathrm{CDCl}_{3}\right)$ spectrum of IIf

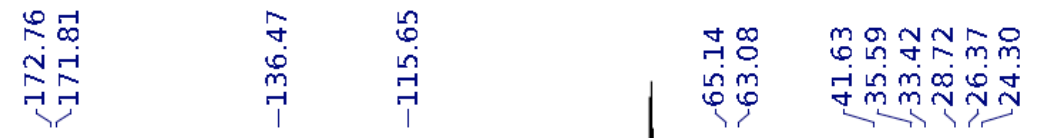

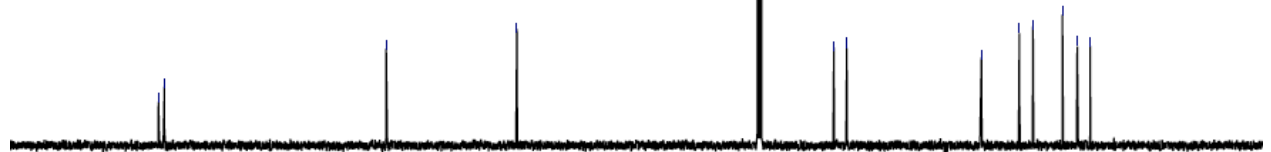

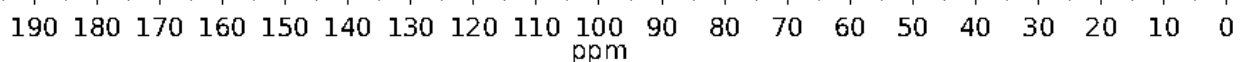

${ }^{13} \mathrm{C}$ NMR (125 MHz, $\left.\mathrm{CDCl}_{3}\right)$ spectrum of IIf 


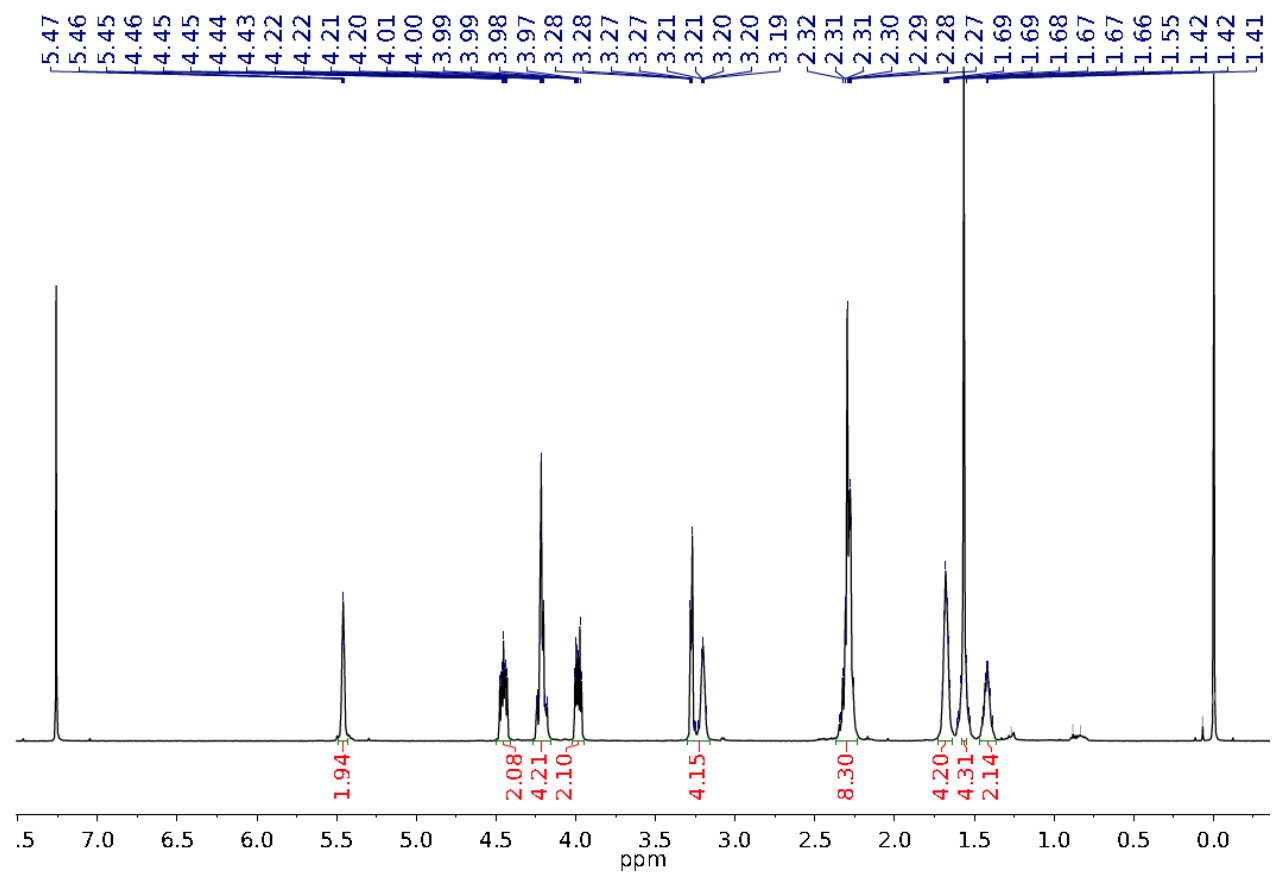

${ }^{1} \mathrm{H}$ NMR $\left(500 \mathrm{MHz}, \mathrm{CDCl}_{3}\right)$ spectrum of IIg

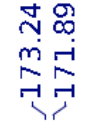

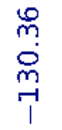

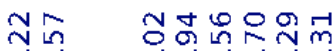
䓪

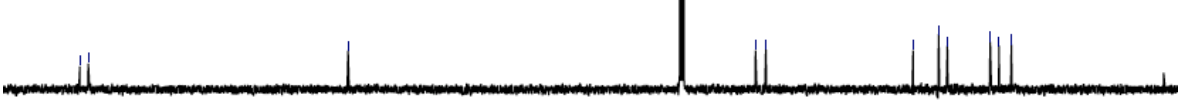

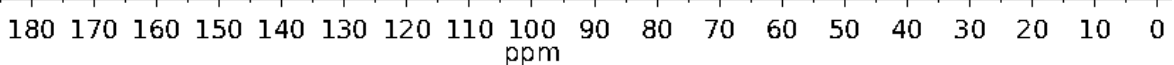

${ }^{13} \mathrm{C} \mathrm{NMR}\left(125 \mathrm{MHz}, \mathrm{CDCl}_{3}\right)$ spectrum of IIg 


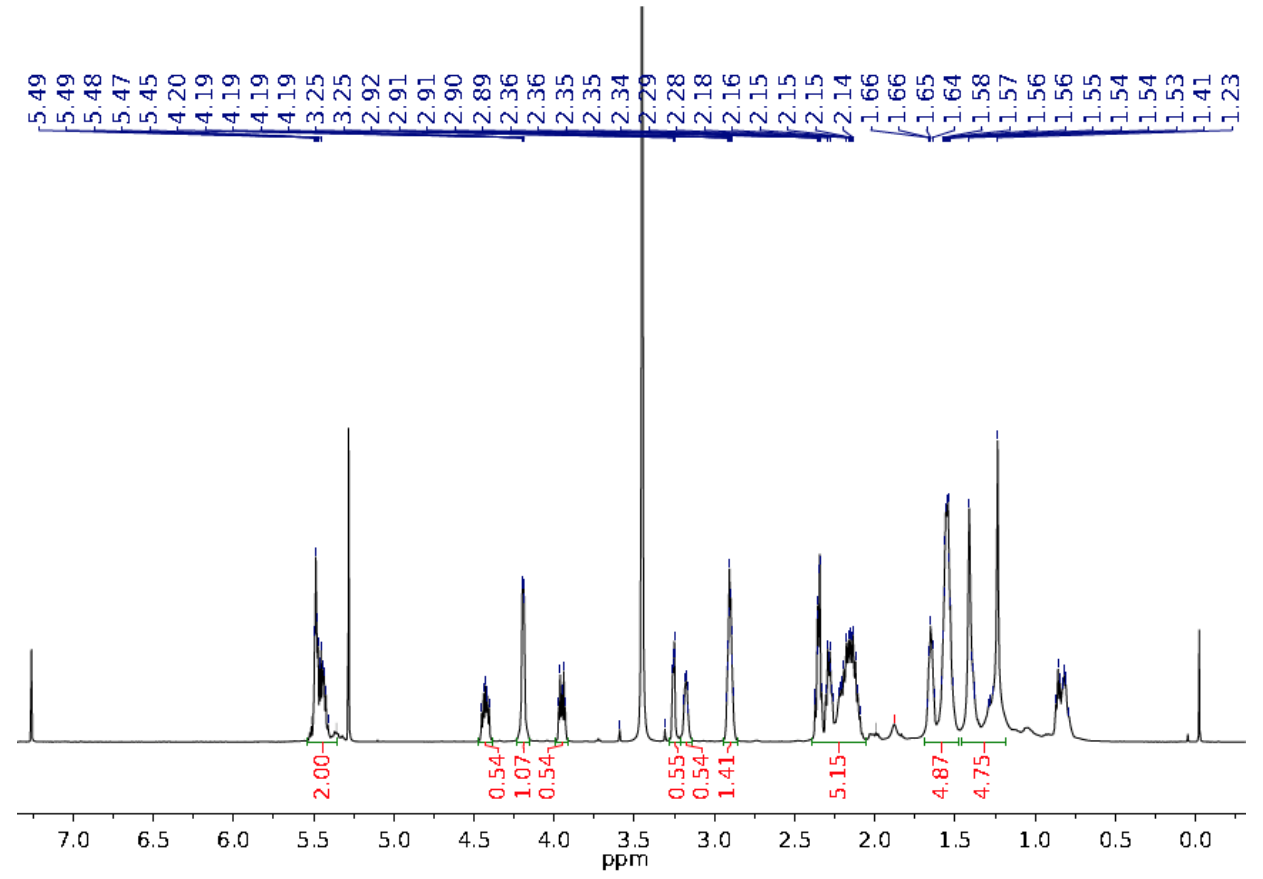

${ }^{1} \mathrm{H}$ NMR $\left(500 \mathrm{MHz}, \mathrm{CDCl}_{3}\right)$ spectrum of polymer PII
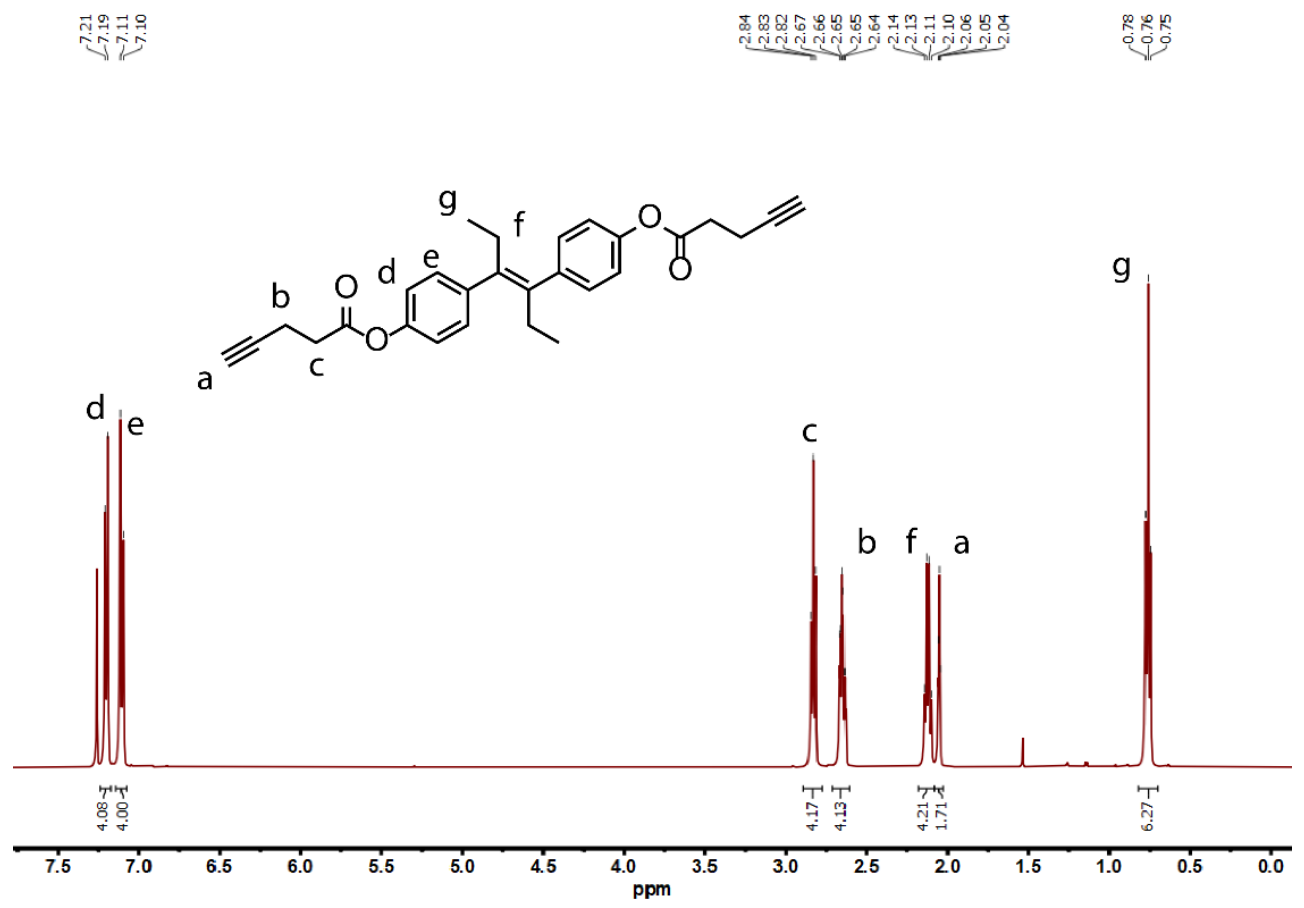

${ }^{1} \mathrm{H}$ NMR (400 MHz, $\mathrm{CDCl}_{3}$ ) spectrum of $\mathbf{3}$ 

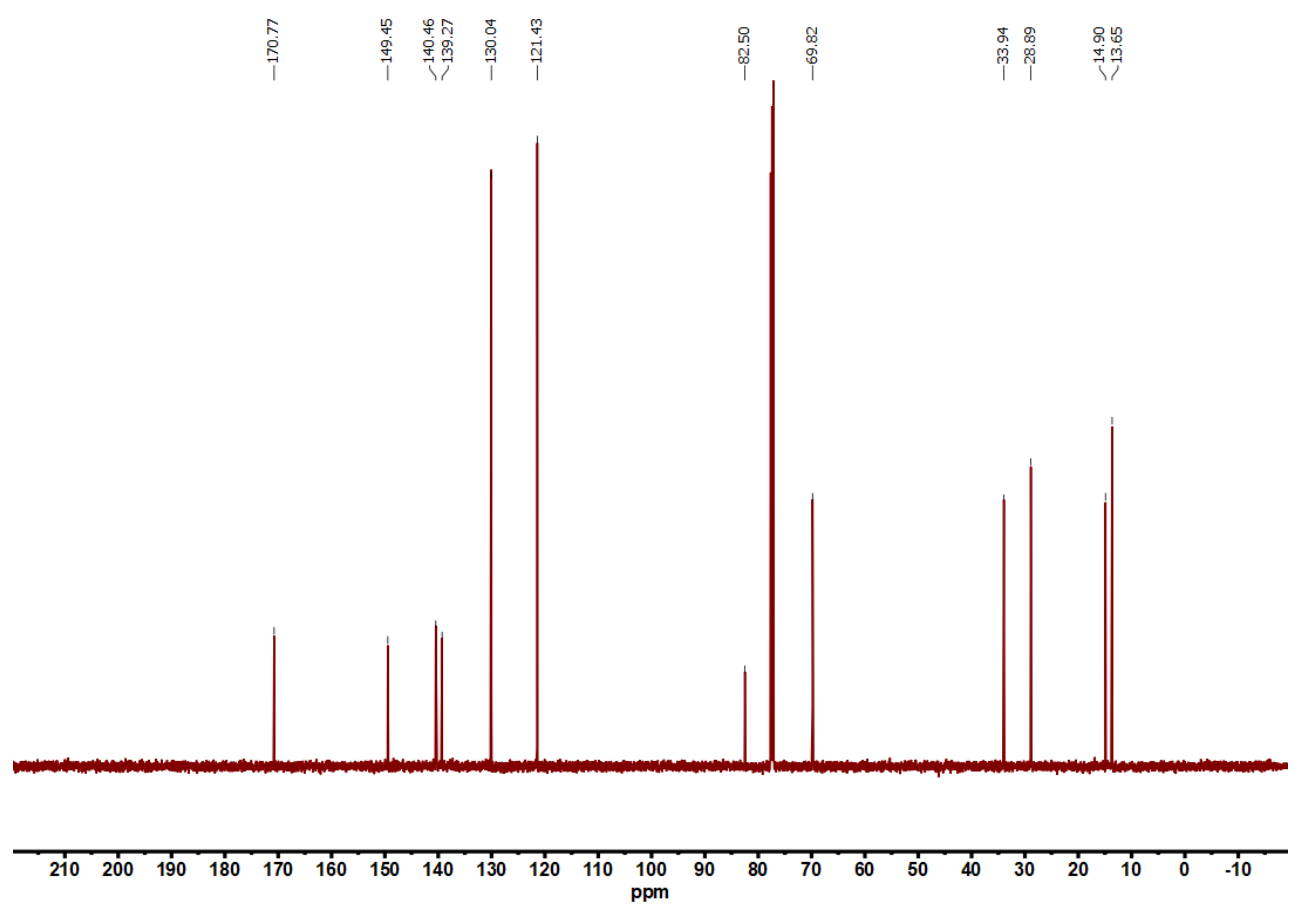

${ }^{13} \mathrm{C}$ NMR $\left(100 \mathrm{MHz}, \mathrm{CDCl}_{3}\right)$ spectrum of $\mathbf{3}$

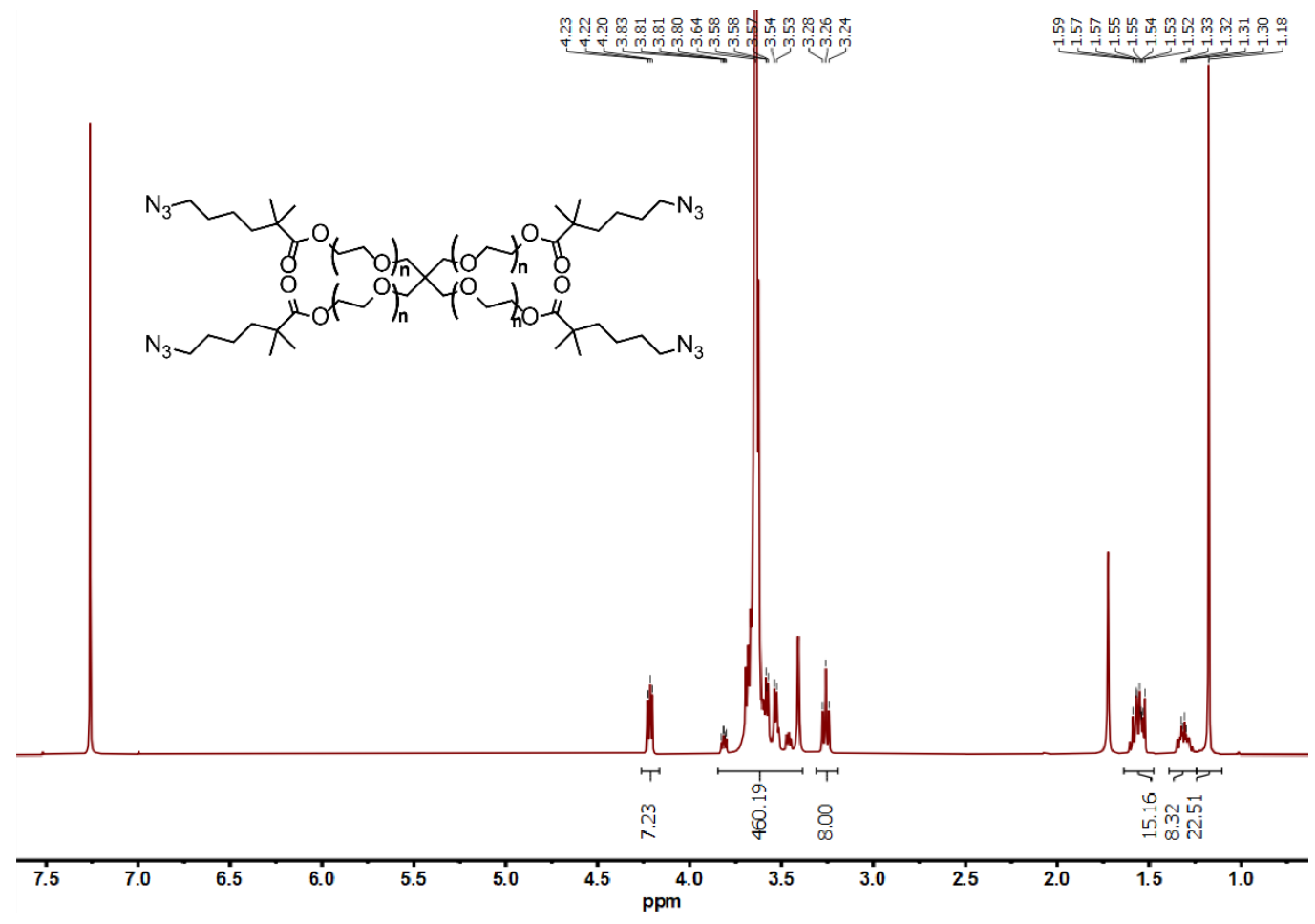

${ }^{1} \mathrm{H}$ NMR (400 MHz, $\mathrm{CDCl}_{3}$ ) spectrum of azide-terminated 4-arm PEG 


\section{References}

(1) Wu, D.; Lenhardt, J. M.; Black, A. L.; Akhremitchev, B. B.; Craig, S. L. Molecular Stress Relief through a Force-Induced Irreversible Extension in Polymer Contour Length. J. Am. Chem. Soc. 2010, 132, 15936-15938.

(2) Klukovich, H. M.; Kouznetsova, T. B.; Kean, Z. S.; Lenhardt, J. M.; Craig, S. L. A Backbone Lever-Arm Effect Enhances Polymer Mechanochemistry. Nat. Chem. 2013, 5 (2), 110-114.

(3) Wang, J.; Kouznetsova, T. B.; Niu, Z.; Ong, M. T.; Klukovich, H. M.; Rheingold, A. L.; Martinez, T. J.; Craig, S. L. Inducing and Quantifying Forbidden Reactivity with Single-Molecule Polymer Mechanochemistry. Nat. Chem. 2015, 7 (4), 323-327.

(4) Wang, J.; Kouznetsova, T. B.; Niu, Z.; Rheingold, A. L.; Craig, S. L. Accelerating a Mechanically Driven Anti-Woodward-Hoffmann Ring Opening with a Polymer Lever Arm Effect. J. Org.

Chem. 2015, 80 (23), 11895-11898.

(5) Kouznetsova, T. B.; Wang, J.; Craig, S. L. Combined Constant-Force and Constant-Velocity Single-Molecule Force Spectroscopy of the Conrotatory Ring Opening Reaction of Benzocyclobutene. Chemphyschem 2017, 18 (11), 1486-1489.

(6) Oberhauser, A. F.; Marszalek, P. E.; Erickson, H. P.; Fernandez, J. M. The Molecular Elasticity of the Extracellular Matrix Protein Tenascin. Nature 1998, 393 (6681), 181-185.

(7) Florin, E. L.; Rief, M.; Lehmann, H.; Ludwig, M.; Dornmair, C.; Moy, V. T.; Gaub, H. E. Sensing Specific Molecular Interactions with the Atomic Force Microscope. Biosens. Bioelectron. 1995, 10 (9-10), 895-901.

(8) Atkinson, S. D. M.; Almond, M. J.; Hollins, P.; Jenkins, S. L. The Photodimerisation of the $\alpha$ - and $\beta$-Forms of Trans-Cinnamic Acid: A Study of Single Crystals by Vibrational Microspectroscopy. Spectrochim. Acta - Part A Mol. Biomol. Spectrosc. 2003, 59, 629-635.

(9) Lin, Y.; Kouznetsova, T. B.; Craig, S. L. Mechanically Gated Degradable Polymers. J. Am. Chem. Soc. 2020, 142 (5), 2105-2109.

(10) Lin, Y.; Kouznetsova, T. B.; Chang, C.-C.; Craig, S. L. Enhanced Polymer Mechanical Degradation through Mechanochemically Unveiled Lactonization. Nat. Commun. 2020, 11, 4987.

(11) Arora, A.; Lin, T.-S.; Beech, H. K.; Mochigase, H.; Wang, R.; Olsen, B. D. Fracture of Polymer Networks Containing Topological Defects. Macromolecules 2020, 53, 7346-7355. 
(12) Zhong, M.; Wang, R.; Kawamoto, K.; Olsen, B. D.; Johnson, J. A. Quantifying the Impact of Molecular Defects on Polymer Network Elasticity. Science 2016, 353 (6305), 1264-1268.

(13) Rivlin, R. S.; Thomas, A. G. Rupture of Rubber. I. Characteristic Energy for Tearing. J. Polym. Sci. 1953, 10 (3), 291-318.

(14) Johnson, F. A.; Radon, J. C. Strain Rate-Crack Speed Relation in Steady State Fracture Processes. Int. J. Fract. 1974, 10 (1), 125-127.

(15) Zehnder, A. T. Fracture Mechanics; Springer London Dordrecht Heidelberg New York, 2012.

(16) Oesterhelt, F.; Rief, M.; Gaub, H. E. Single Molecule Force Spectroscopy by AFM Indicates Helical Structure of Poly(Ethylene Glycol) in Water. New J. Phys. 1999, 1, 6.

(17) Zhang, H.; Li, X.; Lin, Y.; Gao, F.; Tang, Z.; Su, P.; Zhang, W.; Xu, Y.; Weng, W.; Boulatov, R. Multi-Modal Mechanophores Based on Cinnamate Dimers. Nat. Commun. 2017, 8 (1), 1147.

(18) Bell, G. Models for the Specific Adhesion of Cells to Cells. Science 1978, 200 (4342), 618-627.

(19) Smalø, H. S.; Uggerud, E. Ring Opening vs. Direct Bond Scission of the Chain in Polymeric Triazoles under the Influence of an External Force. Chem. Commun. 2012, 48 (84), 10443-10445.

(20) Wang, S.; Panyukov, S.; Rubinstein, M.; Craig, S. L. Quantitative Adjustment to the Molecular Energy Parameter in the Lake-Thomas Theory of Polymer Fracture Energy. Macromolecules 2019, 52, 2772-2777.

(21) Lin, S.; Zhao, X. Fracture of Polymer Networks with Diverse Topological Defects. Phys. Rev. E 2020, 102, 52503. 